\title{
Drooling quantification: correlation of different techniques
}

\author{
Parisa Rashnoo, DDS \\ Department of Otolaryngology-Head and Neck Surgery \\ McGill University, Montreal
}

December 2014

A thesis submitted to McGill University in partial fulfillment of the requirements of

the degree of Master of Science

CParisa Rashnoo, 2014 


\section{Table of Contents}

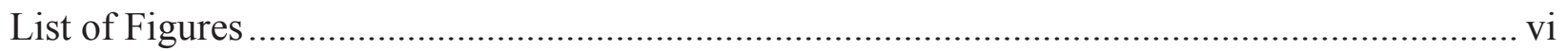

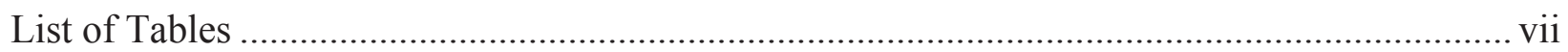

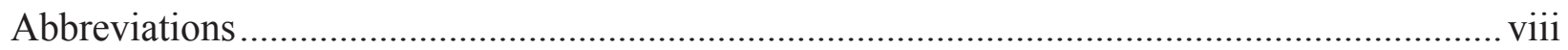

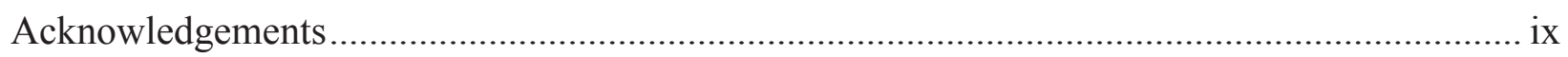

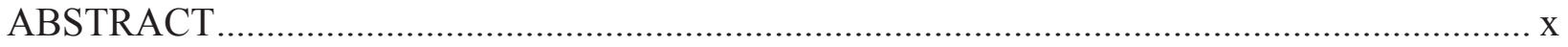

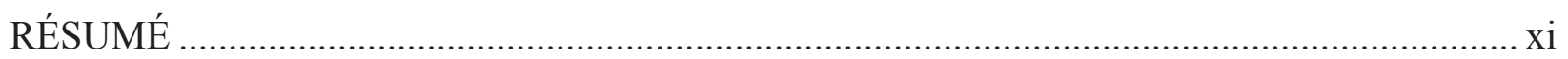

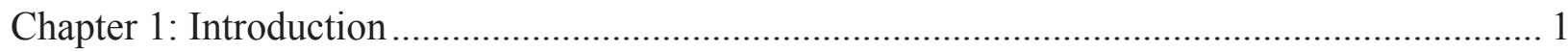

1.1 Definition of the problem and rationale for study .......................................................... 1

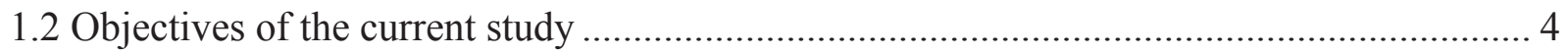

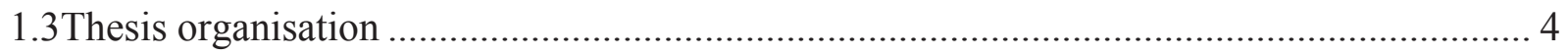

Chapter 2: Literature review - Relevant anatomy and physiology of drooling.............................. 5

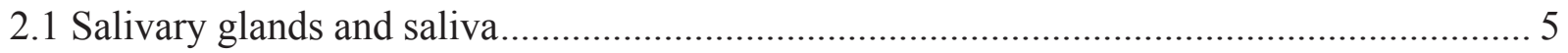

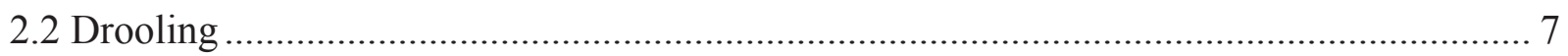

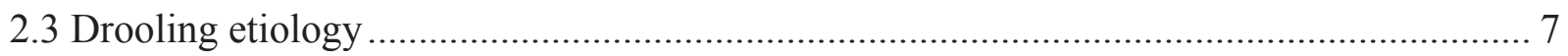

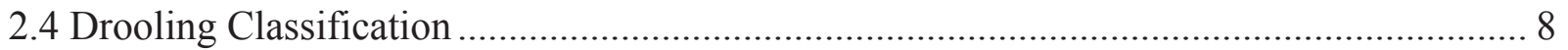

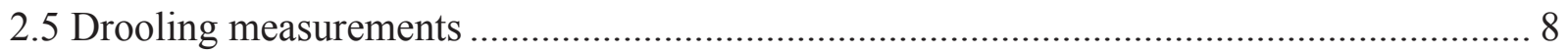

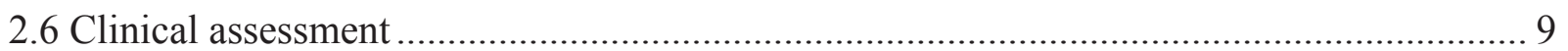




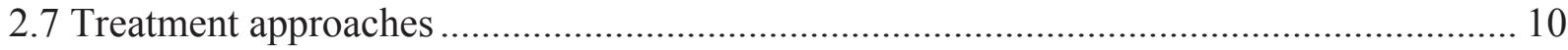

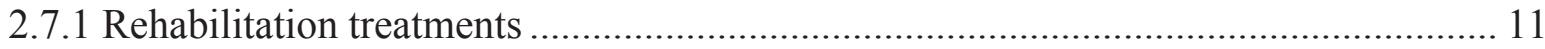

2.7.2 Oral appliances and orthodontic treatments............................................................ 11

2.7.3 Surgical approaches/ radiation therapy ................................................................ 12

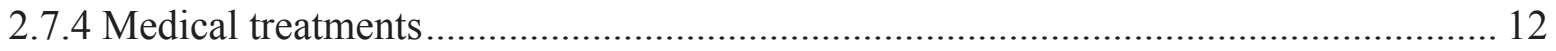

Chapter 3: Literature review- methods for the assessments of drooling .................................. 14

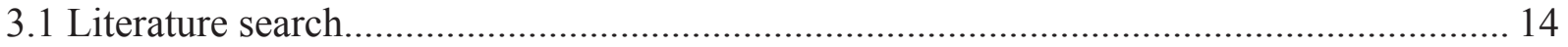

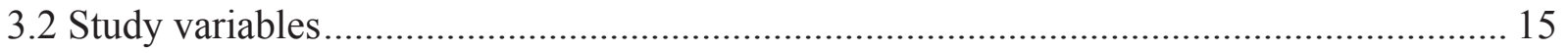

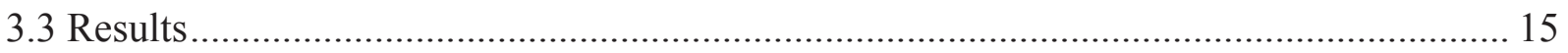

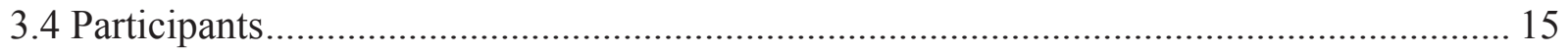

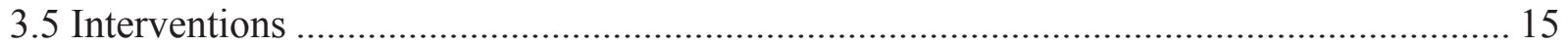

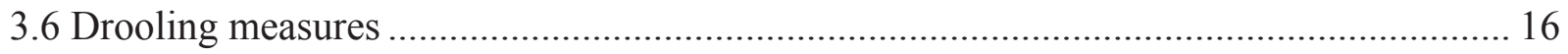

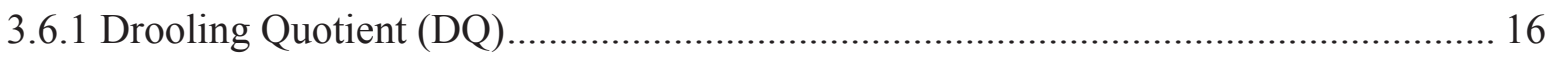

3.6.2 Bib weighing/ number of bib changes ................................................................ 17

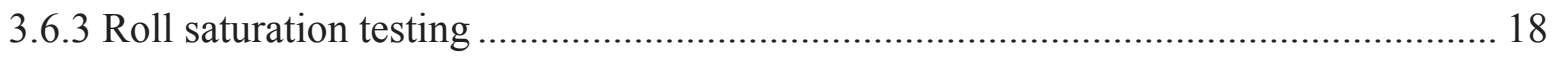

3.6.4 Drooling Severity and Frequency Scale ............................................................... 18

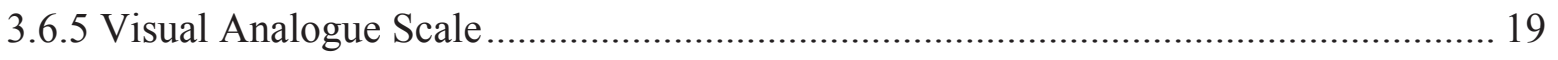

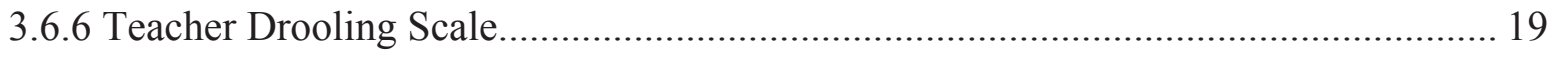

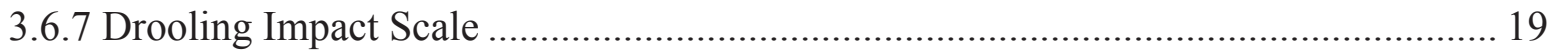




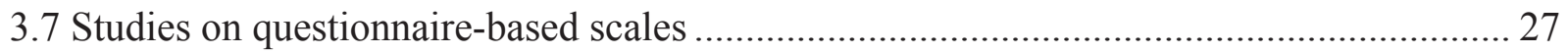

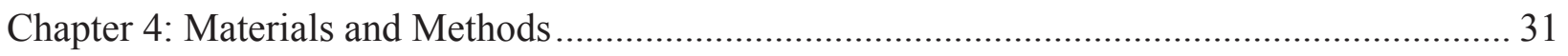

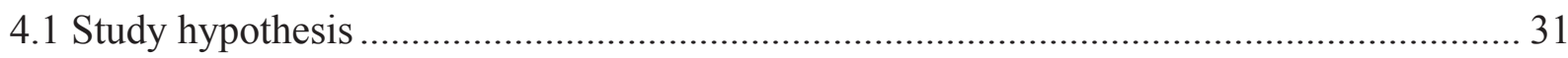

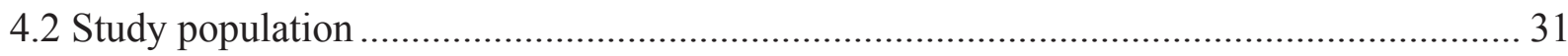

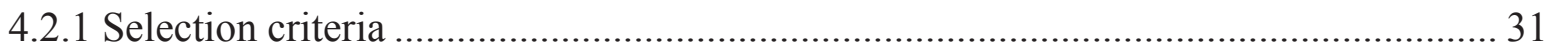

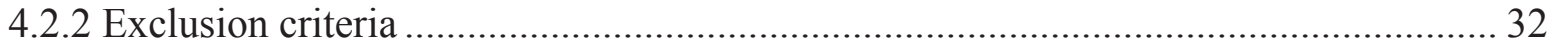

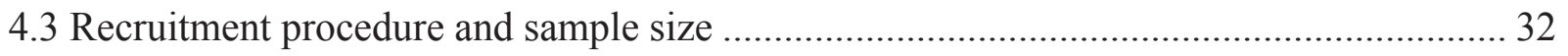

4.4 Demographic characteristics of the study participants …………………………........... 33

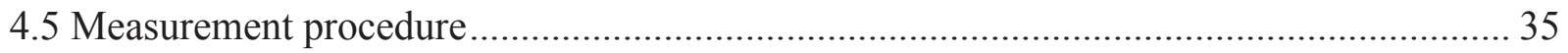

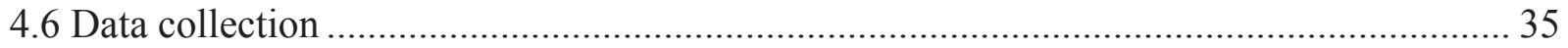

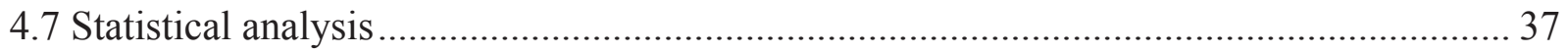

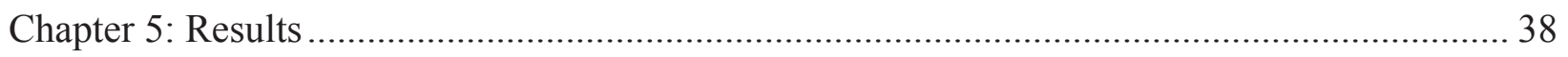

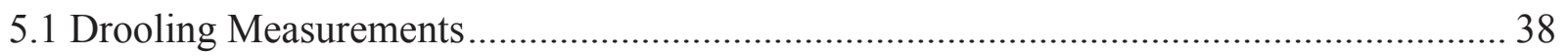

5.2 Correlation between Drooling Quotient and Drooling Severity and Frequency Scale

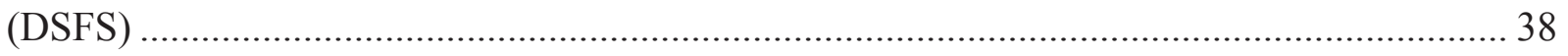

5.3 Correlation between Drooling Severity and Frequency Scale (DSFS) and Number of bib

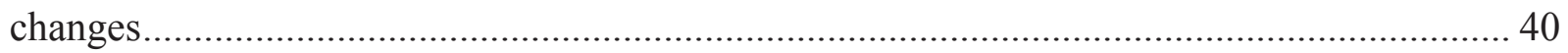

5. 4 Correlation between Drooling Quotient (DQ) and Number of bib changes ...................... 41 
5.5 Correlation between Drooling Quotient (DQ) and Drooling Severity............................ 42

5.6 Correlation between Drooling Quotient (DQ) and Drooling Frequency ......................... 43

5.7 Correlation between Drooling Quotient and other measures........................................ 44

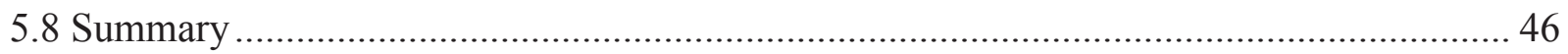

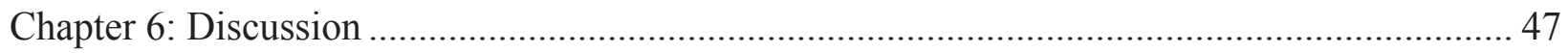

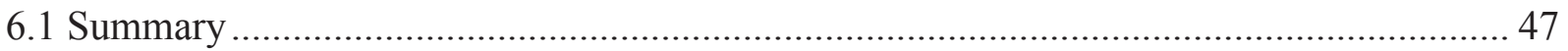

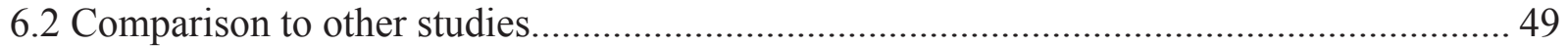

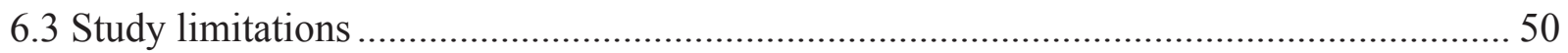

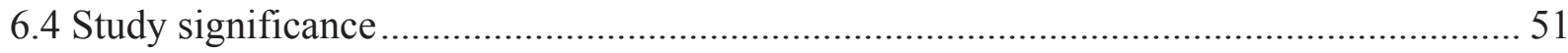

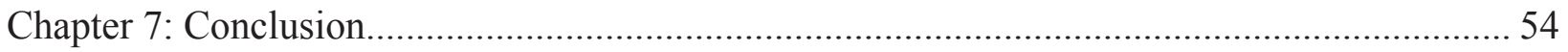

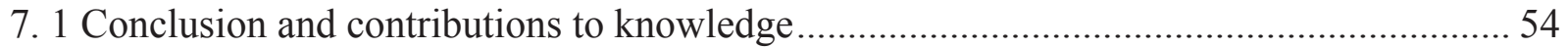

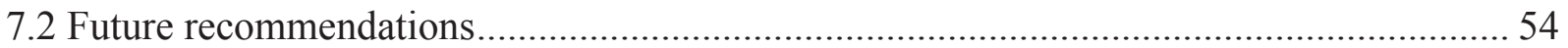

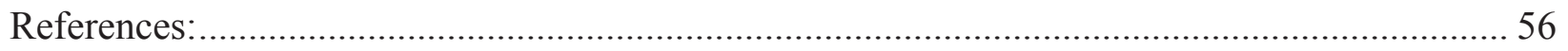

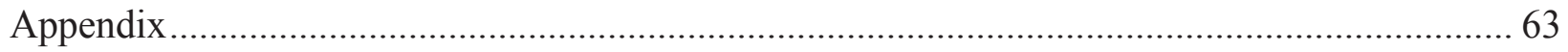




\section{List of Figures}

Figure 1- Detail of submandibular salivary glands, mucous cells and serous cells................... 5

Figure 2- Major salivary glands and their excretory ducts............................................... 6

Figure 3- Association between Drooling-Quotient (DQ) scores and Drooling- Severity-and-

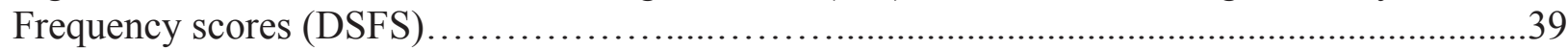

Figure 4- Association between Drooling-Severity-and-Frequency Scale (DSFS) scores and the Number of bib changes scores................................................................................ 40

Figure 5- Association between Drooling- Quotient (DQ) scores and the Number of bib changes

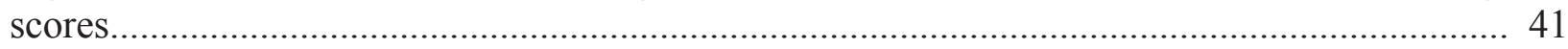

Figure 6- Association between Drooling-Quotient (DQ) scores and Drooling- Severity

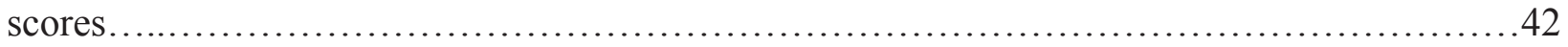

Figure 7- Association between Drooling-Quotient (DQ) scores and Drooling-Frequency

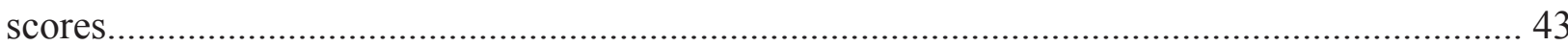




\section{List of Tables}

Table 1- Demographic characteristics of studies using subjective and objective assessments... 24

Table 2- Interventions and drooling measures..................................... 26

Table 3- Correlation between different methods used in the studies......................... 27

Table 4- List of studies used DSFS and number of bib changes......................... 29

Table 5- Demographic characteristic of the study group.................................. 34

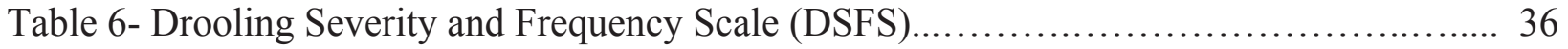

Table 7- Descriptive statistics of population drooling patients characterized................. 38

Table 8-Correlation between DQ and other measures in different subgroups................. 45 


\author{
DQ Drooling Quotient \\ DSFS Drooling Severity and Frequency Scale \\ VAS Visual Analogue Scale \\ DIS Drooling Impact Scale \\ TDS Teacher Drooling Scale \\ QB Quotient de Bavage
}

Abbreviations

MIFB Mesure d'Intensité et de Fréquence de Bavage 


\section{Acknowledgements}

I would like to express the deepest appreciation to my supervisor, Dr. Sam J Daniel, for his invaluable advice, guidance, and patience. This thesis would not be completed without his encouragement and enormous support. I would offer my sincere thanks to my co-supervisor, Dr. Duy-Dat Vu for his insightful comments. I am most grateful to Dr. Bernard Segal, my thesis committee member, for his generous guidance and mentorship through developing my thesis.

A very special thanks goes out to the MAB-Mackay Rehabilitation Centre, and the Saliva Management Clinic for their assistance they provided during this study. I express my gratitude to patients and families who participated in this study.

I want to thank my supportive friends and colleagues in the McGill scientific auditory lab, particularly, Dr. Olubunmi Victoria Akinpelu. A special thanks to the Montreal Children's Hospital library staff who were always eager to help.

Finally, I would like to thank my amazing family for their patience and constant love. I would never have achieved my goals and dreams without their support. In particular, my mother, who has been a source of encouragement and inspiration to me throughout my life. 


\begin{abstract}
Drooling is the unintentional flow of saliva out of the mouth, a condition that can lead to physical and psychological consequences in children and adults alike. Different attempts have been made to eliminate or reduce drooling; these include both non-invasive and invasive techniques. However, since there are no standardized and satisfactory tools to quantify drooling, the effectiveness of the current approaches can be difficult to measure at times. The purpose of this study is to address the need for obtaining a useful and accurate method to assess drooling reduction. This thesis aims to evaluate the association between different techniques for drooling measurements.
\end{abstract}

Using a prospectively collected database from a cohort of one hundred and fifty five participants, a comparison of the following three measurements was made to assess the level of correlation between them: 1- Drooling Quotient (DQ) (performed in two ten-minute sessions by a researcher), 2- Drooling Severity and Frequency Scale (DSFS) (as judged by parents or caregivers) 3- Number of bib changes (as perceived by parents or care givers).

The results showed that there is a high level of agreement between the Drooling Quotient and Drooling Severity and Frequency Scale. However, the Drooling Quotient and number of bib changes did not show significant correlation implying that the Drooling Quotient may not be reflective of the number of bib changes.

The estimated association between the objective DQ and subjective DSFS was high, which implied that the more-easily-obtained DSFS might be used to guide clinical decisions 
regarding treatment of drooling. It is recommended that the validity and reliability of this result be verified in larger studies.

\section{RÉSUMÉ}

Le bavage se définit par l'écoulement involontaire de salive, une condition ayant des conséquences physiques et psychologiques chez les enfants et les adultes. Différentes tentatives ont été menées afin d'éliminer ou de réduire le bavage, notamment à l'aide de techniques noninvasives et invasives. Cependant, vu qu'il n'existe pas d'outil standardisé et satisfaisant pour mesurer l'écoulement de la salive, l'efficacité des approches actuelles peut être difficile à évaluer. Le but de cette étude est de remédier à la nécessité d'obtenir une méthode précise et pratique pour évaluer la réduction de bavage. Notre but est d'évaluer l'association entre les différentes techniques pour mesurer le bavage.

Une étude de cohorte prospective a été menée avec cent cinquante-cinq participants afin de comparer trois mesures de bavage, notamment : 1- le Quotient de Bavage (QB) (réalisé en deux sessions de dix minutes par un chercheur), 2 - la Mesure d'Intensité et de Fréquence de Bavage (MIFB) (selon les parents ou les soignants) 3 - le nombre de changements de bavoirs (tel que perçue par les parents ou les soignants). Une comparaison des trois mesures a été faite pour évaluer le degré de corrélation entre ces mesures.

Les résultats montrent qu'il y a une forte corrélation entre la Mesure d'Intensité et de Fréquence de Bavage (MIFB) et le Quotient de Bavage (QB), ce qui signifie qu'ils peuvent être utilisés de manière interchangeable. Toutefois, le Quotient de Bavage et le nombre de 
changements de bavettes ne semblent pas être corrélés de manière significative, ce qui suggère que le Quotient de Bavage ne reflète pas nécessairement le nombre de changements de bavettes.

La corrélation estimée entre le Quotient de Bavage (QB) objectif et la Mesure d'Intensité et de Fréquence de Bavage (MIFB) est élevée, ce qui implique que la Mesure d'Intensité et de Fréquence de Bavage (MIFB), qui est plus facile à mesurer, pourrait être utilisée afin d'informer les décisions cliniques visant à traiter l'écoulement de salive excessif. Il est recommandé de vérifier la validité et fiabilité de ce résultat à travers des études de plus grande ampleur. 


\section{Chapter 1: Introduction}

\subsection{Definition of the problem and rationale for study}

Drooling is defined as the presence of saliva beyond the margins of the lip and is often referred to as sialorrhea. It is part of normal physical development in newborns and infants, decreasing significantly by eighteen months of age such that by the fourth year, the presence of drooling is considered an abnormal condition. Drooling can become a considerable medical and social problem in children and young adults and it is common in children with neurological and muscular disorders. Its prevalence is up to $58 \%$ in children with cerebral palsy, with one third of these children requiring treatment. Drooling arises more as a consequence of an inability or inefficiency of swallowing rather than excessive production of saliva. (Daniel, 2012; Hockstein, Samadi, Gendron, \& Handler, 2004)

Although drooling is not considered a "life threatening" condition, it could have significant effects on patient's self-esteem and may lead to the psychological burden for both children and their parents. In these patients, there is an associated risk of social rejection or isolation. The physical consequences of drooling include facial skin irritation, halitosis, and perioral infections. The burden of care is also increased because clothes and towels have to be changed multiple times a day (Suskind \& Tilton, 2002). For these reasons, many parents seek medical treatment for their drooling children.

The treatment options available for managing drooling are tailored to the severity of the problem. Different therapeutic strategies that have been used to reduce or eliminate drooling include behavioural therapy, medication, Botulinum toxin injection, and surgery (Daniel, 2012; 
Schroeder et al., 2012). However, due to the complex nature of drooling as a clinical entity, it is not recommended to adopt only one method as the sole approach to the management of drooling. A major limitation of many studies conducted on this subject is the absence of standardized quantitative methods to assess the effectiveness of the treatment, and specifically the inadequacy of these methods to quantify drooling. This drawback makes it difficult to evaluate the effects of different interventions on drooling. This may even impact the conclusions that may be drawn regarding different treatment options(Ekedahl \& Hallen, 1973).

The amount of drooled saliva has been quantified using radioactive isotopes (Ekedahl \& Hallen, 1973). However, this method was found invasive, cumbersome and problematical (Reid, Johnson, \& Reddihough, 2010). Collection devices have also been used; examples of such include suction bags used as collecting units for saliva. Sochaniwsky et al. (1982) introduced a cup-like collection device held against the chin with straps attached on the orthodontic head bonnet; the saliva collected is then suctioned from the cup in to a calibrated test tube where it would be measured. However, the occurrence of leakages makes the measurements inaccurate (Reid et al., 2010; Sochaniwskyj, 1982; Tahmassebi \& Curzon, 2003).

Vanderburg et al reported a subjective method focusing on the effect of a selfmanagement. Here, the duration of dryness (in minutes) is recorded during daily activities (van der Burg, Jongerius, van Limbeek, van Hulst, \& Rotteveel, 2006). Other approaches that have been used include bib weighing and the use of absorbent cotton dental rolls inserted into the oral cavity; some errors have also been reported with these methods (Reid et al., 2010). 
Over the last decade, Drooling Quotient (DQ), a semi-quantitative observational method has been used. It is a direct observational method that assesses the percentage of duration of drooling episodes occurring in two observation sessions(Rapp, 1988). This method has been found to be useful in measuring the severity and frequency of drooling in previous studies. However, due to the long period of evaluation, which is needed to obtain an accurate drooling score, this method is difficult to perform in patients with severe neuromuscular disease. The major drawback with this is that it requires the cooperation of the patient and as such is not ideal for patients who are unable to give maximal cooperation. Many clinicians have therefore used other methods (often subjective) in addition to the DQ. Questionnaire-based subjective assessment of drooling has been described; this involves the measurement of the severity and frequency of drooling. The Drooling Severity and Frequency Scale (DSFS), is one of such subjective methods whereby parents are asked to rate the severity and frequency of drooling. In this scale, drooling severity is given a score ranging from 1 to 5 , and the frequency of drooling is scored between 1 and 4. Other subjective scales include the Teacher Drooling Scale (TDS), Visual Analogue Scale (VAS), Drooling Impact scales (DIS) and the Drooling Rating Scale (Reid et al., 2010).

While the addition of subjective methods is beneficial, their validity has been scarcely studied. This uncertainty, and a desire to give clinicians a simpler tool to guide treatment of drooling, has been the rationale for the research to be described in the current thesis. 


\subsection{Objectives of the current study}

The aim of this study is to assess the correlation of the Drooling Quotient (DQ) with (a) the questionnaire-based Drooling Severity and Frequency Scale (DSFS) and (b) the number of bib changes in a day. It is hypothesized that there is a significant positive correlation between these methods of assessment.

\subsection{Thesis organisation}

Chapter 1 of this thesis has started by introducing the problem to be considered, as well as the thesis aims and specific objectives. Chapter 2 will present an in-depth account of the relevant anatomy and physiology of the salivary gland, which will be followed by an overview of the nature of drooling, and of common approaches to treating drooling. Chapter 3 will review the literature on the different methods of assessing drooling. As will be seen, this extensive review was unable to find any previous studies that determined whether or not the DQ is correlated with other commonly used subjective drooling assessment scales. As a result, this thesis set out to estimate such correlations. Chapter 4 will describe the methods employed in the thesis to do this. Chapter 5 will describe the results of examining the relationship between DQ and two subjective methods of assessment (DSFS and number of bib changes). Chapter 6 will discuss the results presented in Chapter 5 and makes recommendations based on these results. Chapter 7 will summarize the conclusions of this thesis. 


\section{Chapter 2: Literature review - Relevant anatomy and physiology of drooling}

\subsection{Salivary glands and saliva}

There are six major salivary glands (two submandibular, two parotids, and two sublingual glands) and hundreds of minor glands located on the lips, cheek, hard palate, and tongue. They secrete saliva into the mouth through their excretory ducts. Seventy percent of saliva at rest is produced by the submandibular glands. While the parotid gland is the largest of the salivary glands, it produces only $25 \%$ of the saliva. The submandibular gland is made up of a mixture of serous and mucous acini that ultimately drain to the Wharton's duct (Figure 1). The parotid gland is mostly made up of serous acini that ultimately drain through Stensen's duct, which in turn opens opposite to the second maxillary molar (Figure 2). The sublingual gland is the smallest of the three major salivary glands producing about $5 \%$ of saliva and is mostly mucinous. The rest of the saliva is produced by minor salivary glands (Hupp, Tucker, \& Ellis, 2008).

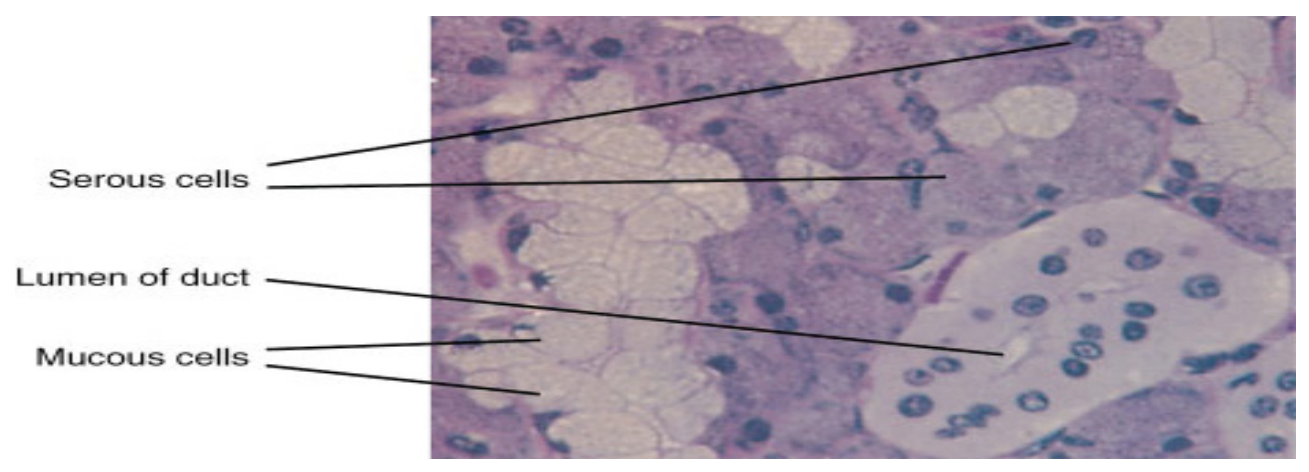

Figure 1- Detail of submandibular salivary gland, showing mucus-secreting mucous cells and enzyme-secreting serous cells. Adapted from Dorland's Illustrated Medical Dictionary (p. 790), 2007, Philadelphia, PA: Elsevier. Reprinted with permission. 
A healthy person produces between 0.5 to 1.5 litres of saliva per day. This drops drastically during sleep. Saliva contains electrolytes, mucus, and antibacterial substances. Saliva also contains enzymes that aid in the digestion of food in the mouth. Moreover, it plays a lubricative role that facilitates swallowing; and a protective role due to its cleansing effect. It washes away adhering food debris and prevents bacterial build-up on teeth surfaces. Reduction of saliva flow therefore contributes to increasing dental plaque formation and results in dental caries and periodontal disease(Hupp et al., 2008).

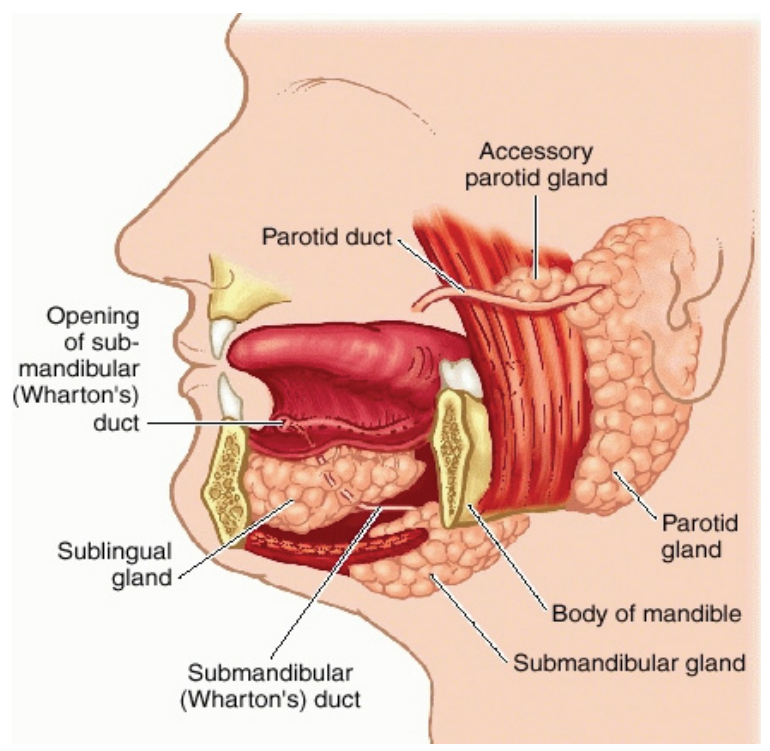

Figure 2- Major salivary glands and their excretory ducts. Adapted from Dorland's Illustrated Medical Dictionary (p. 790), 2007, Philadelphia, PA: Elsevier. Reprinted with permission.

Saliva secretion and flow are under the autonomic nervous system control. The parasympathetic nervous system innervates the major salivary glands and promotes secretion of saliva. It is carried via cranial nerves. The parotid gland receives its parasympathetic input from 
the glossopharyngeal nerve (CN IX) via the otic ganglion, while the submandibular and sublingual glands receive their parasympathetic input from the facial nerve $(\mathrm{CN}$ VII) via the submandibular ganglion. The sympathetic nervous system controls the flow of the saliva by causing the contraction of the muscle fibers within the salivary ducts. Sympathetic innervation of the salivary glands takes place via preganglionic nerves in the thoracic segments T1-T3 which synapse in the superior cervical ganglion with postganglionic neurons that release norepinephrine, which is then received by $\beta$-adrenergic receptors on the acinar and ductal cells of the salivary glands, leading to an increase of saliva secretion (Figure 3)(Erasmus et al., 2009).(Costanzo, 2006)

\subsection{Drooling}

Drooling is a common complaint in children with neurological or muscular disorders. It has been reported that up to $58 \%$ of children with cerebral palsy suffer from drooling, and a third of these patients require treatment due to the severity of the drooling (Schroeder et al., 2012).

\subsection{Drooling etiology}

Drooling is often caused by neuromuscular disorders, sensory dysfunction (cerebral palsy, intellectual disability), motor dysfunction; excessive production of saliva (teething, adverse effects of medication, gastro-esophageal reflux and toxin exposure), or anatomical problems (malocclusion, orthodontic problems, macroglossia). However, impairment of the swallowing function is the primary cause of drooling rather than hyper secretion of saliva. Cerebral palsy and intellectual disability are considered the most common causes in children; 
while Parkinson's disease is commonly implicated in adults. Other causes including bulbar palsy, pseudobulbar palsy, and stroke are less common(Hockstein et al., 2004).

\subsection{Drooling Classification}

Drooling can be classified as anterior or posterior. The physical consequences of anterior drooling are halitosis, angular cheilitis, and chronic chapped, irritated facial skin. On the other hand, posterior drooling causes a wet voice, congested breathing, and complications such as chronic respiratory disorders that develop secondary to saliva aspiration (Jongerius et al., 2001).

\subsection{Drooling measurements}

Previously, radioactive isotopes have been used for quantitative measurement of

drooling. In a study by Ekedahl technetium ${ }^{99 \mathrm{~m}}$ was used intravenously to evaluate effects of treatments against drooling. The amount of drooled saliva was calculated by measuring the radioactivity of the bibs where saliva was collected and of saliva samples (Ekedahl \& Hallen, 1973). Although the dose of radioactive isotope for drooling treatment evaluation is small, this method was found invasive, cumbersome and problematic (Reid et al., 2010).

Urine or suction bags have also been used as collecting units for saliva. In a study designed by Sochaniwskyj a cup like collection device was held against the chin with straps attached to the orthodontic head bonnet (Schroeder et al., 2012). The tight seal created by the pressure against the chin and lower lip could prevent the leakage. Drooled saliva was suctioned from the cup into a calibrated test tube where it would be measured. However, leakage is a major disadvantage in all methods using collection devices (Reid et al., 2010; Tahmassebi \& Curzon, 2003). 
In another study a different method was used to measure drooling with a focus on the effect of a self-management approach. Here the latency of being dry (in minutes) was recorded during daily activities. Other approaches such as bib weighing have been used, although some errors have been reported with this. Other ways of saliva quantification are the use of absorbent cotton dental rolls inserted into the oral cavity, with the weight of the rolls measured and compared pre and post insertion (Reid et al., 2010; van der Burg et al., 2006)

Drooling Quotient (DQ) is a semi-quantitative observational method. It measures drooling by recording the absence or presence of saliva on the lip in two ten-minute observational sessions with a sixty-minute interval.

Questionnaire-based subjective assessment of drooling, which has been described in the literature, involves the measurement of the severity and frequency of drooling using different methods. In the Drooling Severity and Frequency Scale (DSFS) parents are asked to rate the severity and frequency of drooling. In this scale, drooling severity is given a score ranging from one to five, and the frequency of drooling is scored between one and four. Teacher drooling scale (TDS) is another method which scores drooling severity from one to five. Other subjective measurement scales are Visual Analogue Scale (VAS) and, Drooling Impact Scales (DIS) which use a ten-point scale. Another questionnaire-based method is the Drooling Rating Scale which includes questions related to physical, quality of life, and caregiver issues (Reid et al., 2010).

\subsection{Clinical assessment}

Drooling is a multifactorial problem; therefore its clinical assessment and management requires a multidisciplinary approach. The MAB-Mackay drooling management clinic in which 
this study was conducted, offers multiple treatment options for drooling patients including rehabilitative therapies, anti-cholinergic medication, Botulinum toxin injection, and surgery. Each patient is given the best treatment option based on the consensus of a multidisciplinary team in partnership with the parents. This team includes a paediatrician, an occupational therapist, a speech and language pathologist, a dentist, a neurologist, a paediatric otolaryngologist, a social worker, a researcher, and a coordinator (Daniel, 2012).

During the clinical examination of the patient, the medical team evaluates all the possible factors that can contribute to drooling; these include but are not limited to posture, neurological status, dental health, medication, and otolaryngological problems. Evaluation of swallowing, feeding, and drinking habits at rest and during activities is performed. Also, saliva drooling is quantified using subjective and objective drooling scales in order to evaluate the impact of drooling on the patients' quality of life and to estimate the possible outcomes of the available treatment options (Daniel, 2012; Hockstein et al., 2004).

\subsection{Treatment approaches}

The treatment options for drooling include conservative approaches such as behavioral programs, biofeedback, and postural change; Invasive procedures include medication, radiation, and surgery. There is lack of consensus as to the most effective approach, as this would vary from patient to patient depending on their specific needs.

Dental problems like malocclusions and periodontal disease are diagnosed and treated by a dentist and/or an orthodontist. Adenoid and tonsil problems are evaluated and managed by an otolaryngologist. Head and neck postural control are usually addressed by an occupational 
therapist. Observation could be the best option for children under the age of four (Fairhurst \& Cockerill, 2011).

\subsubsection{Rehabilitation treatments}

This is a non-invasive approach including behavioural and oral motor therapy. Behaviour therapy for drooling aims to assist patients to perform self-management skills. It can improve behaviours such as swallowing, wiping, closing the mouth, and controlling the head. Oral-motor and oral-sensory therapies consist of a variety of activities to improve lip closure, oral-motor skills including lip mobility, tongue mobility, and jaw stability, and to improve oral and facial muscle strength and swallowing (Fairhurst \& Cockerill, 2011; Yam, Yang, Abdullah, \& Chan, 2006).

\subsubsection{Oral appliances and orthodontic treatments}

Different types of oral appliances have been used to control saliva over the years. Limbrock et al. designed the removable acrylic appliance referred to as "Castillo-morals" in the mid-1970s. These appliances reduced drooling in 67\% cases and improved chewing and swallowing (Limbrock, Fischer-Brandies, \& Avalle, 1991). Another oral appliance, the Innsbruck sensorimotor activator (ISMAR) was developed in order to provide jaw stability as well as lip closure and tongue mobility (Johnson et al., 2004).

Oral appliances have been applied for drooling reduction in children, although they are usually not appropriate for children with severe disability due to their short time effect (Erasmus et al., 2009). In previous studies, chin cups, lip halters, vibrators, and lip sensors were used to increase muscle tone in jaw muscles and assist in lip closure. In babies, palatal training appliances have 
been used for the treatment of feeding and swallowing difficulties. These appliances have produced some degree of success in drooling reduction(OLIVER, 1987).

\subsubsection{Surgical approaches/ radiation therapy}

Surgery is usually offered when conservative approaches fail or the parents are unwilling to use the conservative approach. Surgical management of drooling include removal of salivary glands, salivary duct clipping, rerouting of salivary ducts, and trans-tympanic neurectomy. Removal of tonsils and surgical management of gastropharyngeal reflux are other treatment options.

Surgery is however associated with operative complications. In a previous study two major complications including ranula and sialodentitis were reported following duct ligation. Minor complications also occurred after surgery such as saliva thickening and tongue swelling (Peyton Shirley, Scott Hill, Woolley, \& Wiatrak, 2003; Shirley, Hill, Woolley, \& Wiatrak, 2003).

Radiation therapy has also been used in the management of drooling although this could result in xerostomia. Also, malignancies may occur ten to fifteen years after receiving the treatment.(Hockstein et al., 2004)

\subsubsection{Medical treatments}

Anti-cholinergic medications including Scopolamine and Glycopyrrolate have been used in the medical management of drooling. They block the parasympathetic innervations of the salivary glands. However, anti-cholinergic have systemic side effects such as constipation, 
urinary retention, orthostatic hypotension, bradycardia, irritability, and drowsiness (Hockstein et al., 2004).

Botulinum toxin, a neurotoxic substance, produced by the bacterium clostridium botulinum has also been used in the management of drooling. Multiple studies have demonstrated the effectiveness of Botulinum toxin in the treatment of drooling in the past decade. This potent toxin is taken up by the end plate of autonomic cholinergic fibers, including secretary parasympathetic fibers in salivary glands and inhibits acetylcholine release irreversibly. Drooling has been controlled either by injecting both parotid and submandibular glands or the parotid alone (Mancini et al., 2003; Savarese, Diamond, Elovic, \& Millis, 2004; Suskind \& Tilton, 2002). 


\section{Chapter 3: Literature review- methods for the assessments of drooling}

\subsection{Literature search}

The literature review has shown that the Drooling Quotient (DQ), the Drooling, Severity \& Frequency Scale (DSFS), and the number of bib changes have been frequently used to describe drooling status. However, it is unknown how well these drooling measures relate to each other. This chapter will try to determine whether any previous studies have explored this question.

A PubMed search was conducted for articles published between 1946 and 2014 using the key words sialorrhea or drooling. This was further limited to articles related to clinical studies that reported the use of at least one of the drooling measurement scales including the objective DQ, the subjective DSFS and number of bib changes. Articles, which used other methods apart from these, were excluded.

Among 85 articles that used different types of techniques for drooling assessments on interventions; the majority used other types of questionnaire-based methods of assessment. Eight studies used only Drooling Severity and Frequency Scale (DSFS) to measure drooling. Three of the studies used number of bib changes and DSFS to assess drooling. (Table 4)

Eighteen (18) studies were reported the use of combined approach (with the DQ and another assessment methods e.g. teacher drooling scale (TDS), Drooling Severity and Frequency Scale (DSFS), Visual analogue scale (VAS), Cotton Roll Saturation test and number of bib changes. (Table 1) 


\subsection{Study variables}

The data extracted from the studies included the name(s) of author(s), year of publication, sample size, age range, gender distribution, and drooling diagnosis (Table 1). Data on the interventions and outcome measures in the various studies were also extracted and analyzed. (Table 2)

\subsection{Results}

Eighteen studies satisfied the inclusion criteria and were included for data analyses. Three of the studies had a large sample size (more than 100), while the others had smaller number of participants. Five studies had less than 10 subjects in total.

\subsection{Participants}

Studies using the combined subjective and objective approach had a total of 662 different subjects including 317 (48\%) males and 345 (52\%) females. The age range is between 1.6 to 22 years old. These participants had different types of neurological disorders including cerebral palsy / other developmental disabilities, mental disabilities and brain injuries. (Table 1)

\subsection{Interventions}

Table 2 shows the various interventions offered in the studies I reviewed. The following interventions were reported: Botulinum toxin-A (14 studies) Anti-reflux medication (1 study), saliva control surgeries versus Botulinum toxin-A injection (2 studies), Botulinum toxin-B injection (1 study), and saliva control surgery alone (1 study). 


\subsection{Drooling measures}

In the studies summarized in Table 1, Drooling reduction was reported by scores using 7 different types of drooling measures: three objective and four subjective. These were the Drooling Quotient (DQ), weight and number of bib changes, saturation cotton roll test, Visual Analogue Scale (VAS), Drooling Severity and Frequency Scale (DSFS), and the Teacher Drooling Scale (TDS).

\subsubsection{Drooling Quotient (DQ)}

The Drooling Quotient represents a direct observational method for drooling measurement. This is a semi quantitative approach to measure frequency of drooling by counting each occasion of saliva loss.

This method was originally developed by Rapp. He measured drooling by sampling observations in a class using a device called teacher prompt. In this study the teacher put the ear plugs attached to the small box in to his ears. Forty cues occurred in a period of ten minutes. Drooling score was recorded by the teacher as present or absent. In this method, drool strings is defined as drooling, whether it is continuous or falling when the bleeps occurs (Rapp, 1988).

The modified form of the DQ was proposed by Reddihough et al. They enhanced the reliability between testers by making some modifications. They measured drooling in three separate periods of ten minutes before, during and after intervention. Drooling was scored in 15 seconds intervals. The number of drooling episodes was scored out of 40 (the number of 15 seconds intervals in 10 minutes) in each period of ten minutes. Drooling score was presented as 
percentage. The author defined the episodes of drooling as new saliva present beyond the margin of the lip to avoid double counting. (Reddihough, Johnson, Staples, Hudson, \& Exarchos, 1990)

Van Hulst et al. redesigned the DQ to 15 seconds intervals over 5 minutes. The author stated that measuring DQ in 10 minutes is time consuming and costly and no validity and reliability is available for DQ10. They concluded that DQ5 and DQ10 can be used interchangeably with sustained its validity and reliability (van Hulst, Lindeboom, \& Jongerius, 2012).

There are some disadvantages for the DQ. The differences in saliva quantity cannot be measured accurately, because the volume of stringy drools is greater than saliva drops. As number of drooling occasions is counted in Drooling Quotient, drooling frequency could be recorded precisely. With respect to the variability of drooling severity throughout a day, to achieve an accurate drooling severity score, long period of evaluation is required (Reid et al., 2010).

\subsubsection{Bib weighing/ number of bib changes}

Bothwell et al. designed a study to measure the effect of Botulinum toxin injection on drooling in children with cerebral palsy. Drooling observation was performed with the subject wearing dental bibs around the neck to collect saliva. The bibs were three -ply cellulose plus polyback dental bibs. The weight of the saliva was assessed four weeks before and after injection. Although some evidence supports this method's validity, some measurement errors may occur due to evaporation, saliva missing the bibs and other liquids being spilled. In another clinical study, the weight and the number of bibs used per day before and after Botulinum-B 
injection were used as two objective measurements of sialorrhoea (Basciani et al., 2011; Bothwell et al., 2002).

\subsubsection{Roll saturation testing}

Ellies applied this method in a study to evaluate the effect of Botulinum toxin injection on saliva flow reduction. Cotton dental rolls were placed into the mouth for 5 minutes and then centrifuged to obtain the clear saliva. This approach described a similar technique where two dental rolls are inserted into the oral cavity for two minutes. An electronic scale was used to measure the weight of cotton rolls before and after oral insertion (Ellies et al., 2002; HassinBaer, Scheuer, Buchman, Jacobson, \& Ben-Zeev, 2005) . Although, this is a non- invasive method that quantifies the volume of produced saliva, it cannot measure the amount of saliva beyond the margin of the lower lip (Jongerius et al., 2001).

\subsubsection{Drooling Severity and Frequency Scale}

This method was designed by Thomas-Stonell and Greenberg in 1988. All patient are assigned a rank according to the following categories of drooling severity; 1- dry : never drools; 2- mild: only the lips wet; 3-moderate: wet on the lips and chin ; 4- Severe (drools to extent that clothing becomes damp) 5- profuse: clothing, hands, tray, and objects become wet. Frequency of drooling is also ranked as 1- never drools ; 2- occasional drooling ; 3-frequent drooling ; 4constant drooling. The scores from the severity and frequency categories are then added to give a combined drooling ranking/score from 2 to 9 (Thomas-Stonell \& Greenberg, 1988). 


\subsubsection{Visual Analogue Scale}

Visual analogue scale (VAS) measures subjective drooling characteristics or attitudes that cannot be measured directly. The severity of drooling is assessed on a10 point visual scale. Care givers mark the extent of drooling on a10-cm line. The VAS score is obtained by measuring the position of the mark in millimeters from the left end of the scale on a scale from 0 to 100 , where 100 indicating severe drooling. (Scheffer \& al. 2010) A modified version was described as 0 : (never drools), 10: (Constant drooling) (Savarese et al., 2004).

\subsubsection{Teacher Drooling Scale}

Teacher Drooling Scale (TDS) is also used in measurement of Drooling Severity and Frequency following saliva-control interventions. This scale consists of five statements related to the severity and frequency of the drooling. The caregiver has to circle the description that represents the best the amount of drooling observed during a day. The score ranges from 1 to 5 ; 1- No drooling, 2- Infrequent drooling, small amount 3- occasional drooling, on and off all day 4- frequent drooling, but not profusely 5- constant drooling, always wet (Reid et al., 2010).

\subsubsection{Drooling Impact Scale}

Reid et al. designed a scale to measure the impact of drooling in children with developmental disabilities. This subjective method appeared to be reliable and valid for the evaluation of changes in drooling in these children. This questionnaire-based scale was developed with a focus on questions related to frequency and severity of drooling as well as burden of care (number of bibs and clothing changes needed throughout the day) and its effect of children's quality of life. All items are scored on a10 point scale (Reid et al., 2010). 


\subsubsection{Drooling Rating Scale}

This scale was used by Suskind et al. to evaluate effectiveness of Botulinum toxin injection on drooling. In order to measure drooling changes, a questionnaire is developed including fourteen questions related to "physical", "quality of life" (QOL), and "caregiver" issues(Suskind \& Tilton, 2002).

Heine et al. assessed the effect of anti-reflux medication on drooling using direct observation of drooling (DQ) in combination with a questionnaire-based scale of Drooling Severity and Frequency Scale to increase the accuracy of assessment. They found no significant reduction in drooling using their method. They however did not evaluate the relationship between DQ and DSFS (Heine, Catto-Smith, \& Reddihough, 1996).

Jongerius et al. assessed the effect of Botulinum toxin- A using absorbent cotton rolls and Drooling Severity and Frequency Scale. The clinical observations varied among the patients. They reported more than 50\% reduction in drooling, although they did not assess the relation between their subjective and objective responses. In a similar study conducted a few years later, they used DQ, TDS, VAS to measure drooling reduction after injections, their subjective and objective result were in accordance with each other, although correlation between them was not evaluated statistically (Jongerius et al., 2001; Jongerius, van Hulst, van den Hoogen, \& Rotteveel, 2005).

Savarese et al. evaluated Botulinum toxin-A using VAS, bib changes, and weight of dental rolls. They reported significant reduction in drooling after injections. Subjective responses 
varied among parents. They did not report the relation between their subjective and objective responses (Savarese et al., 2004).

Hassin Baer in a study on Botulinum toxin used Drooling Severity and Frequency Scale along with roll saturation test. Their study showed poor results in drooling reduction. Their subjective assessments including global clinical impression were consistent with the severity and frequency scales. However, statistical analysis was not performed to evaluate the relationship between their subjective and objective scales (Hassin-Baer et al., 2005).

Lin et al. in another study evaluated the effect of Botulinum toxin-A using Drooling Severity and Frequency Scale and Drooling Quotient. Their results showed significant differences between groups in the DSFS and the DQ scales at follow-up sessions. Again, correlation between these scales was not statistically evaluated (Lin, Shieh, Cheng, \& Yang, 2008).

Bothwell et al. in a similar study on Botulinum toxin-A measured drooling reduction using the DSFS, DQ, and bib weighing. Objective and subjective responses varied among patients. They did not assess the correlations between the measures (Bothwell et al., 2002). Marina et al. in a study on Botulinum toxin used Drooling Severity and Frequency Scale, number of bib changes, and VAS to assess drooling reduction. They reported drooling reduction after injections. Again, they did not evaluate the relationship between their objective and subjective evaluations. (Marina, Sani, Hamzaini, \& Hamidon, 2008)

Scheffer et al. conducted a study on Botulinum toxin using DQ, VAS, and TDS. Their results showed objective and subjective response rate of $50 \%$. In another study in the same year, 
they compared Botulinum toxin injections with surgery for drooling control using DQ and VAS. Drooling reduction was found to be significant after both interventions. Also in another study (2013) with surgery as an intervention for drooling control, they used DQ and VAS to assess drooling reduction. In all studies, drooling was improved significantly on the different scales; however, the association between subjective and objective responses were not assessed (Scheffer et al., 2010).

Baschiani et al. in a study on Botulinum toxin-B measured drooling using severity frequency scale, weight and number of bib changes per day. Drooling reduction was reported in all cases. However, the relationship between their objective and subjective responses was not addressed (Basciani et al., 2011).

Erasmus et al. also in a similar study evaluated Botulinum toxin-A effectiveness, where drooling reduction was measured using DQ and TDS. Drooling improvement was shown after injections on both objective and subjective scales. Again, in this study, objective and subjective responses were not compared (Erasmus et al., 2011).

$\mathrm{Wu}$ et al. evaluated Botulinum toxin-A injections on drooling. The authors evaluated drooling reduction measuring the severity of drooling. They also used the number of bib changes, and gauze weighing. In this study, objective results showed significant reduction in drooling after injections, but the subjective scales did not show the same effect. Correlation between objective and subjective responses was not assessed statistically (Wu et al., 2011).

Jeung et al. evaluated the effect of Botulinum toxin-A on drooling using Drooling Count (DC), DFS, and the TDS. All measures showed significant improvement in drooling. The 
response rate to Botulinum toxin in the DC was higher than the TDS (Jeung, Lee, Kim, \& Yeo, 2012).

Van Hulst et al. in a study on Botulinum toxin / surgery for drooling control, recalculated the original DQ 10 in to a 5-minute score (DQ5). The authors concluded that DQ5 and DQ10 can be used interchangeably. In this study they assessed the correlation between VAS and DQ during activity and rest. The statistical analysis showed a weak correlation between VAS and DQ versions (van Hulst et al., 2012).

Nordgarden et al. evaluated Botulinum toxin effect using DQ, VAS, and Cotton rolls to measure drooling severity and flow rate. The results showed discrepancies between subjective and objective responses. They did not assess the relation between the scales statistically (Nordgarden et al., 2012).

On the whole, these studies demonstrate that a combination of objective and subjective scales is useful to assess drooling reduction accurately. However, the above mentioned studies have limitations and could not conclude that their drooling assessment methods were reliable enough to measure drooling reduction. Most of the studies reported drooling improvement on subjective and objective methods, but no statistical assessment was performed in order to find the relationship between the subjective and objective scales. Four studies however did not find an agreement in the subjective and objective responses (Jeung et al., 2012; Lin et al., 2008; Nordgarden et al., 2012; Wu et al., 2011). Thus, it is difficult to conclude that drooling reduction was assessed accurately. 
In two other studies, although their responses were in agreement, statistical analyses were not done, thus, their results cannot be generalized and should be interpreted cautiously (Hassin-Baer et al., 2005; Jongerius et al., 2005).

Only one author assessed the correlation between VAS and DQ responses statistically and concluded that there is a weak agreement between them indicating that they cannot be used interchangeably (van Hulst et al., 2012). Further studies are therefore needed to compare subjective and objective responses and their level of agreement.

Based on the literature, most of the authors used DQ as an objective assessment method. Also, DSFS and number of bib changes are easy to perform and frequently used in previous studies on drooling control. The current study for the first time examines the relationship between Drooling Quotient (DQ) and the Drooling Severity and Frequency Scale, as well as the number of bib changes as methods of assessing drooling control.

Table 1- Demographic characteristics of studies using subjective and objective assessments

\begin{tabular}{ccccc}
\hline Study & $\begin{array}{c}\text { Sample } \\
\text { size (n) }\end{array}$ & $\begin{array}{c}\text { Age } \\
\text { year }\end{array}$ & $\begin{array}{c}\text { Gender } \\
(\mathrm{M} / \mathrm{F})\end{array}$ & Diagnosis \\
\hline Heine et al. (1996) & 24 & $4.5-18.6$ & $11 / 13$ & $\mathrm{CP}$ \\
\hline Jongerius et al. (2001) & 3 & $13,11,13$ & $2 / 1$ & $\mathrm{CP}$ \\
\hline Suskind et al. (2002) & 20 & $8-21$ & $4 / 13$ & $\mathrm{CP} /$ brain injury \\
\hline Bothwell et.al. (2002) & 9 & $4-17$ & 4.5 & Neurological \\
\end{tabular}




\begin{tabular}{|c|c|c|c|c|}
\hline Jongerius et al. (2005) & 1 & 9 & $1 / 0$ & $\mathrm{CP}$ \\
\hline Savarese et al. (2004) & 21 & $5-18$ & - & $\mathrm{CP}$ \\
\hline Hassin Baer et al. (2005) & 9 & $6-18$ & $6 / 3$ & $\begin{array}{c}\text { Neurological } \\
\text { disorders }\end{array}$ \\
\hline Lin et al. (2008) & 13 & $12-15$ & - & $\mathrm{CP}$ \\
\hline Marina et al. (2008) & 20 & $>12$ & $7 / 13$ & $\begin{array}{c}\mathrm{CP} / \text { other } \\
\text { Neurological } \\
\text { disorders }\end{array}$ \\
\hline Scheffer et al. (2010) & 19 & $5-17$ & $10 / 9$ & $\mathrm{CP}$ \\
\hline Scheffer et al. (2010) & 133 & $3-7$ & $77 / 54$ & $\begin{array}{c}\mathrm{CP} / \text { other } \\
\text { neurological } \\
\text { disorders }\end{array}$ \\
\hline Baschiani et al. (2011) & 27 & $5-15$ & $15 / 12$ & $\begin{array}{c}\text { Neurological } \\
\text { disorders }\end{array}$ \\
\hline Erasmus et al. (2011) & 126 & $3-21$ & $81 / 45$ & $\begin{array}{c}\mathrm{CP} / \text { mental } \\
\text { disability }\end{array}$ \\
\hline Wu et al. (2011) & 20 & $3-16$ & $9 / 11$ & $\mathrm{CP}$ \\
\hline Jeung et al. (2012) & 17 & $3-11$ & $9 / 8$ & $\begin{array}{c}\text { Neurological } \\
\text { disorders }\end{array}$ \\
\hline Van Hulst et al. (2012) & 162 & $3-22$ & $61 / 101$ & $\begin{array}{c}\mathrm{CP} / \text { developmental } \\
\text { Disabilities }\end{array}$ \\
\hline Nordgarden et al. (2012) & 6 & $10-18$ & $2 / 4$ & $\mathrm{CP}$ \\
\hline Scheffer et al. (2013) & 23 & $7-20$ & $14 / 9$ & $\begin{array}{c}\mathrm{CP} / \text { other } \\
\text { neurological } \\
\text { disorders }\end{array}$ \\
\hline
\end{tabular}


Table 2- Interventions and drooling measures

\begin{tabular}{|c|c|c|}
\hline Study & Interventions & Measures \\
\hline \multirow[t]{2}{*}{ Heine et al. (1996) } & Anti reflux & DSFS/DQ \\
\hline & Medication & \\
\hline Jongerius et al. (2001) & Botulinum toxin $-\mathrm{A}$ & DSFS/Absorbent cotton rolls \\
\hline Suskind et al. (2002) & Botulinum toxin $-\mathrm{A}$ & $\begin{array}{l}\text { Drooling rating scale / Dental roll } \\
\text { weight }\end{array}$ \\
\hline Bothwell et al. (2002) & Botulinum toxin- $\mathrm{A}$ & $\begin{array}{l}\text { DSFS/ Drooling Frequency / Bib } \\
\text { weighing / DQ/ TDS }\end{array}$ \\
\hline Savarese et al. (2004) & Botulinum toxin- $\mathrm{A}$ & $\begin{array}{l}\text { VAS / Bib changes/ Weight of } \\
\text { dental rolls }\end{array}$ \\
\hline Hassinbaer et al. (2005) & Botulinum toxin $-\mathrm{A}$ & $\begin{array}{l}\text { DSFS/ Roll saturation test/ } \\
\text { Global clinical impression }\end{array}$ \\
\hline Jongerius et al. (2005) & Botulinum toxin $-\mathrm{A}$ & $\mathrm{DQ} / \mathrm{TDS} / \mathrm{VAS}$ \\
\hline Lin et al. (2008) & Botulinum toxin- A & DSFS/ DQ/ saliva weight \\
\hline Marina et al. (2008) & Botulinum toxin $-\mathrm{A}$ & VAS/ Bib changes/ DSFS \\
\hline Scheffer et al. (2010) & Botulinum toxin -A vs. Surgery & DQ / TDS \\
\hline Scheffer et al. (2010) & Botulinum toxin $-\mathrm{A}$ & $\mathrm{DQ} / \mathrm{VAS} / \mathrm{TDS}$ \\
\hline Baschiani et al. (2011) & Botulinum toxin $-\mathrm{B}$ & $\begin{array}{l}\text { DSFS/ weight and number of bib } \\
\text { changes }\end{array}$ \\
\hline Erasmus et al. (2011) & Botulinum toxin $-\mathrm{A}$ & TDS / DQ \\
\hline Wu et al. (2011) & Botulinum toxin $-\mathrm{A}$ & $\begin{array}{l}\text { Bib changes / Drooling severity / } \\
\text { Gauze weighing }\end{array}$ \\
\hline Jeung et al. (2012) & Botulinum toxin $-\mathrm{A}$ & DC/ TDS / DSFS \\
\hline Van Hulst et al. (2012) & Botulinum toxin $-\mathrm{A} /$ surgery & VAS / DQ5/ DQ10/ DIS / DSFS \\
\hline Nordgarden et al. (2012) & Botulinum toxin $-\mathrm{A}$ & DQ / VAS / cotton rolls \\
\hline Scheffer et al. (2013) & Salivary duct ligation & DQ / VAS \\
\hline
\end{tabular}


Table 3- Correlation between different methods used in the studies

\begin{tabular}{|c|c|c|c|c|}
\hline Author/Year & Method1 & Method 2 & Method 3 & Correlation done \\
\hline Heine et al. (1996) & DQ & DSFS & VAS & No \\
\hline $\begin{array}{l}\text { Jongerius et al. } \\
(2001)\end{array}$ & Weight of dental rolls & $\begin{array}{l}\text { Number of bib } \\
\text { changes }\end{array}$ & VAS & No \\
\hline $\begin{array}{l}\text { Hassan Baer et al. } \\
(2005)\end{array}$ & Roll saturation test & DSFS & - & No \\
\hline Lin et al. (2008) & DQ & DSFS & - & No \\
\hline $\begin{array}{l}\text { Bothwell et al. } \\
(2002)\end{array}$ & DQ & DSFS & - & No \\
\hline $\begin{array}{l}\text { Marina et al. } \\
(2008)\end{array}$ & DSFS & $\begin{array}{l}\text { Number of bib } \\
\text { changes }\end{array}$ & VAS & No \\
\hline $\begin{array}{l}\text { Scheffer et al. } \\
(2010)\end{array}$ & DQ & TDS & VAS & No \\
\hline $\begin{array}{l}\text { Bachiani et al. } \\
\text { (2011) }\end{array}$ & DQ & $\begin{array}{l}\text { Weight /number of } \\
\text { bib changes }\end{array}$ & - & No \\
\hline $\begin{array}{l}\text { Erasmus et al. } \\
\text { (2011) }\end{array}$ & DQ & TDS & - & No \\
\hline Wu et al. (2011) & Gauze weighing & $\begin{array}{l}\text { Number of bib } \\
\text { changes }\end{array}$ & $\begin{array}{l}\text { Drooling } \\
\text { severity }\end{array}$ & No \\
\hline Jeung et al. (2012) & $\mathrm{DC}$ & DSFS & TDS & No \\
\hline Van Hulst (2012) & DQ5/DQ10 & VAS & DSFS/DIS & Yes \\
\hline $\begin{array}{l}\text { Nordgarden et al. } \\
\text { (2012) }\end{array}$ & DQ & Cotton rolls & VAS & No \\
\hline
\end{tabular}

\subsection{Studies on questionnaire-based scales}

Eleven of the included studies used only DSFS and number of bib changes to assess drooling changes. These studies are summarized on Table 4. 
Stern along with Mier et.al used subjective assessment of DSFS in a study on medication for drooling control. Mato et al. evaluated drooling changes in a similar study on medication for drooling control using DSFS and number of bib changes. Their subjective assessment showed significant drooling reduction after the intervention; however, they encountered difficulty in drooling quantification in disabled patients, which possibly accounts for the variability of their results. They concluded that although objective quantitative assessment of drooling is useful to assess treatment outcomes, it may not be feasible in patients with disability due to limited cooperation. Alternative semi-quantitative methods may be helpful in this group of patients. Mier et al. reported that the subjectivity of parents' evaluation of drooling improvement and side effects was the major limitation of their study. To deal with this subjectivity, the authors conducted a blinded cross over protocol, they also defined the nature of drooling clearly by line drawings at each drooling scale(Mato et al., 2010; Mier et al., 2000; Stern, 1997).

Alrefai (2008), Hay et al. (2011), and Gok et al. (2013) used DSFS to assess the effect of Botulinum toxin injection in children with drooling. Schroder et al. (2012) also applied DSFS and the number of bib changes to assess the effect of Botulinum toxin. According to Alrefai, using subjective methods is easier for parents to assess treatment effect and to judge changes in drooling based on the number of times they wipe the saliva; they also are able to notice when the effect of medicine wear off. They also found that objective methods such as using dental rolls are difficult to carry out in children for fear of choking. In another study by Hay (2011), subjective rating scales were shown as non-aggressive qualitative tools for drooling measurement; they indicate drooling reduction in daily situations versus quantitative objective tools which only represent decrease of salivary flow that does not necessarily shows change of drooling severity. 
Furthermore, objective scales are time-consuming and impractical in the clinical settings (Alrefai, Aburahma, \& Khader, 2009; Gok et al., 2013; Hay \& Penn, 2011).

In other studies, some authors also used DSFS or number of bib changes as method of choice to evaluate their interventions (Table 4). In some of the studies, measurement scales was scored by the researcher before and after interventions(Chang \& May-Kuen Wong a, 2001; Martin \& Conley, 2007), while in another study parents were asked to rate the drooling changes(Burton, Leighton, \& Lund, 1991).

Table 4- List of studies using DSFS and number of bib changes

\begin{tabular}{|c|c|c|c|}
\hline Author & Year & Intervention & Drooling measure \\
\hline Burton & 1991 & $\begin{array}{l}\text { Drooling control } \\
\text { surgery }\end{array}$ & $\begin{array}{l}\text { Number of bib } \\
\text { changes }\end{array}$ \\
\hline Stern & 1997 & Medication & DSFS \\
\hline Mier & 2000 & Medication & DSFS \\
\hline Chang & 2001 & Laser therapy & DSFS \\
\hline Martin & 2007 & Surgery & DSFS \\
\hline Alrefai & 2008 & Botulinum toxin & DSFS \\
\hline Mato & 2010 & Medication & $\begin{array}{l}\text { DSFS/number of bib } \\
\text { changes }\end{array}$ \\
\hline Hay & 2011 & Botulinum toxin & DSFS \\
\hline Schroedor & 2012 & Botulinum toxin & $\begin{array}{l}\text { DSFS/number of bib } \\
\text { changes }\end{array}$ \\
\hline Chanu & 2012 & Surgery & DSFS \\
\hline GokGolcan & 2013 & Botulinum toxin & DSFS \\
\hline
\end{tabular}


In summary, it appears that no previous study has effectively characterized the associations between different measures of drooling status. The remainder of this thesis will evaluate whether such associations exist. 


\section{Chapter 4: Materials and Methods}

\subsection{Study hypothesis}

This thesis will test the hypothesis that there is a significant positive correlation between (i) the Drooling Quotient (DQ), (ii) the Drooling, Severity and Frequency Scale (DSFS), and (iii) the number of bib changes per day, so that any one of these measures might be used for guidance of clinical decisions regarding treatment of drooling. In particular, that the more-easily-obtained subjective assessment measures (DSFS or number of bib changes) might be used instead of the more time-consuming DQ measure.

In order to test this hypothesis, I queried a database of a prospectively collected cohort of patients referred to a saliva management clinic and who met the inclusion criteria.

\subsection{Study population}

\subsubsection{Selection criteria}

The criteria for inclusion in the analysis were:

1- The presence of drooling, regardless of severity and frequency of drooling, drooling is defined as a presence of saliva beyond the lower lip margin or a string of saliva falling from the mouth for more than two seconds

2- Patients aged from four to eighteen years old

3- Diagnosis of mild to moderate neurological disorder

4- Good cooperation allowing for DQ measurement in two ten-minute sessions (while they are focusing and while they are distracted) 
5- Family communicates in English or French

\subsubsection{Exclusion criteria}

1- Absence of drooling

2- Patients less than four years old or more than eighteen years old

3- Presence of severe motor dysfunction

4- Inability to obtain the DQ score or to follow the steps required in measurement procedures

5- Children/caregivers do not communicate in French or English

6- Incomplete medical records or missing data on any of the measurement outcomes

\subsection{Recruitment procedure and sample size}

Subjects were patients of the saliva management clinic of MAB-MacKay rehabilitation center in Montreal. This is a multidisciplinary clinic comprised of a paediatric otolaryngologist, a pediatrician, a dentist, a neurologist, an occupational therapist, and a social worker. It was set up in 2003 to manage drooling in children with a variety of neuromuscular disorders including $\mathrm{CP}$, intellectual disability, and developmental delay (Daniel, 2012). The initial assessment consists of separate evaluations by the rehabilitation team, medical team, and a social worker. Each team analyzes the factors that contribute to drooling. Finally all team members meet as a group with the family and offer the most appropriate treatment option based on the patients' needs. Drooling is quantified as per the number of bibs per day, the Drooling Quotient, and the Drooling Severity and Frequency Scale. 
All patient data was retrieved from a prospectively collected database. Patients selected were those seen at the saliva management clinic between January $1^{\text {st }} 2010$ and December $31^{\text {st }}$ 2013, who met the inclusion criteria stated previously. Ethical approval was obtained from the Institutional Review Board.

\subsection{Demographic characteristics of the study participants}

A total of one hundred and fifty five patients were recruited for this study. There were 74

females and 81 males with ages ranging between 4 to 18 years (mean age $=9.03$ ). The main etiology for drooling consisted of developmental delays $(n=62)$, neurological disorders $(n=64)$, other disabilities including intellectual disability, dyspraxia, syndrome and airway problems $(n=29)$. The sample size was based on the number of patients who attended the saliva management clinic during the time period above and who met the inclusion or exclusion criteria. The participant's demographic characteristics are summarized in Table 5. 
Table 5- Demographic characteristic of the study group $(\mathrm{N}=155)$

\begin{tabular}{lcc}
\hline Characteristics & Frequency & Percent (\%) \\
\hline Gender & & \\
& & \\
\hline Female & 74 & 47.74 \\
\hline Male & & 52.26
\end{tabular}

\begin{tabular}{lcc}
\hline Diagnosis & & \\
\hline Developmental delay & 64 & 41.29 \\
\hline Neurological disorders & 62 & 40.00 \\
\hline Intellectually disabled & 9 & 5.81 \\
\hline Syndrome & 12 & 7.74 \\
\hline Dyspraxia & 1 & 0.65 \\
\hline Airway/occlusion & 7 & 4.52 \\
\hline
\end{tabular}

Mean SD

\begin{tabular}{lll}
\hline Age & 9.038 & 4.32
\end{tabular}




\subsection{Measurement procedure}

In all enrolled patients, drooling was measured subjectively and objectively using standardized parameters.

The measurements were taken in the following order: 1- Drooling Severity and Frequency Scale, as judged by the parents or main caregiver. 2- Number of bib changes as reported by parents or care givers 3- Drooling Quotient (DQ).

\subsection{Data collection}

The Drooling Quotient (DQ) was assessed by two trained raters. First, before starting the Drooling Quotient measurement, saliva was wiped off the chin. Then during the next 10 minutes, the presence or absence of saliva was recorded every 15 seconds. The Drooling Quotient was expressed as a percentage of observed drooling occasions out of 40 (the number of intervals in 10 minutes).

In order to measure drooling subjectively, two methods were used. The first method, DSFS was used to quantify the severity and frequency of drooling on a scale of 2 to 9 . In this scale, parents or care givers were asked to rate the severity and frequency of drooling, classifying severity of drooling using a 5-level domain ranging from 1 (dry) to 5 (profuse drooling). The frequency of drooling was classified using a 4-level domain ranging from 1(no drooling) to 4 (constant drooling). (Table 6)

The second subjective measurement method was based on the opinion of parents or caregivers. They were asked the number of times they changed bibs due to excessive drooling throughout the day. Parents were asked to fill out the questionnaire consisting of questions 
related to the DSFS and number of bib changes. Each subjective scale was assessed one time. In all measurement sessions, drooling was defined as saliva beyond margin of the lower lip or string of saliva falling from the mouth more than two seconds without the patient wiping themselves.

Table 6- Drooling Severity and Frequency Scale (DSFS)

Severity

Dry (never drool) 1

Mild (only lips wet)

2

Moderate (wet on lips and chin) 3

Severe (drools to extent that clothing becomes damp) 4

Profuse 5

\section{Frequency}

\begin{tabular}{ll}
\hline Never drools & 1 \\
\hline Occasionally (not every day) & 2 \\
\hline Frequently (part of everyday) & 3 \\
\hline Constantly & 4
\end{tabular}




\subsection{Statistical analysis}

To assess the association between various measures, the non-parametric Spearman's rank correlation coefficient was used (Lehman, 2005). For all statistical tests, the level of significance was set at less or equal to 0.05. All analyses were performed using SAS for windows. DQ was assessed by two observers. The inter-rater reliability was determined using Pearson's correlation coefficient employing the statistical package SAS for windows. 


\section{Chapter 5: Results}

\subsection{Drooling Measurements}

As outlined in Chapter 4, the drooling status of patients was assessed during a single session using 3 measures: (i) the Drooling Severity and Frequency Scale (DSFS), (ii) the number of bib changes, and (iii) the Drooling Quotient (DQ). Table 7 shows the resulting means and standard deviations (SD) of these 3 measures in all patients. The mean and standard deviation for the DSFS was $6.69 \pm 1.67$ (5.02-8.36). Based on the DSFS (which could range from 2 to 9), the mean DSFS score of $6+.69$ indicated that the population typically exhibited moderate to severe drooling.

Table 7- Descriptive statistics of population drooling patients characterized

\begin{tabular}{|c|c|c|c|}
\hline \multirow{2}{*}{$\begin{array}{l}\text { Drooling severity and } \\
\text { Frequency Scale (DSFS) }\end{array}$} & \multirow{2}{*}{$\begin{array}{l}\text { Number of bib } \\
\text { changes }\end{array}$} & \multirow{2}{*}{\multicolumn{2}{|c|}{$\begin{array}{l}\text { Drooling } \\
\text { Quotient (DQ) }\end{array}$}} \\
\hline & & & \\
\hline Mean & Mean & Mean & SD \\
\hline 1.67 & 3.28 & 19.17 & 15.60 \\
\hline
\end{tabular}

Number of subjects $(\mathrm{N})=155$

\subsection{Correlation between Drooling Quotient and Drooling Severity and Frequency}

\section{Scale (DSFS)}

To evaluate the association between the Drooling Quotient (DQ) score and the subjective Drooling Severity \& Frequency Scale (DSFS) score, the measures obtained during the single assessment session were compared. Figure 3 shows a scatter plot of these measures in the 155 
patients. As the DSFS increased from 4 to 9 , the DQ also tended to increase from 0 to 40 . To characterize the association between these measures, the non-parametric Spearman's rank correlation coefficient was computed. It was found to be significantly $(\mathrm{P}<0.001)$ non-zero, having a positive value of 0.886 , indicating high level of association between DQ and DSFS.

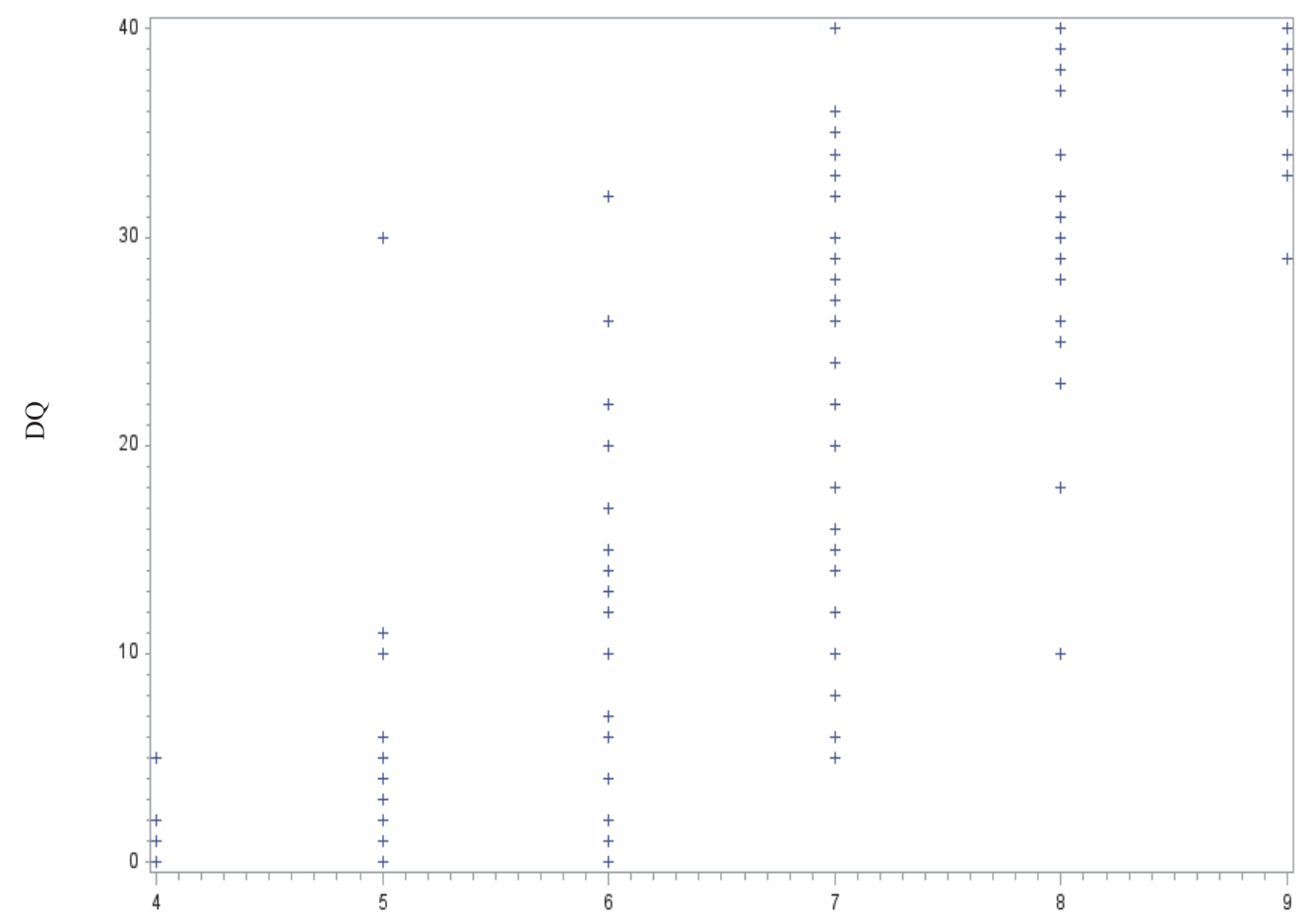

DSFS

Figure 3- Association between Drooling-Quotient (DQ) scores and Drooling- Severity-andFrequency Scale (DSFS) scores. The Spearman rank correlation coefficient was significantly non-zero, having a positive value of 0.886 . 


\subsection{Correlation between Drooling Severity and Frequency Scale (DSFS) and}

\section{Number of bib changes}

To evaluate the association between Drooling Severity \& Frequency Scale (DSFS) and the number of bib changes, the measures obtained during the single assessment session were compared. Figure 4 shows a scatter plot of these measures in the 155 patients. To characterize the association between measures, the non-parametric Spearman rank correlation coefficient was computed. It was found to be significantly $(\mathrm{P}<0.001)$ non-zero, having a positive value of 0.335 , indicating a moderate association between DSFS and number of bib changes.

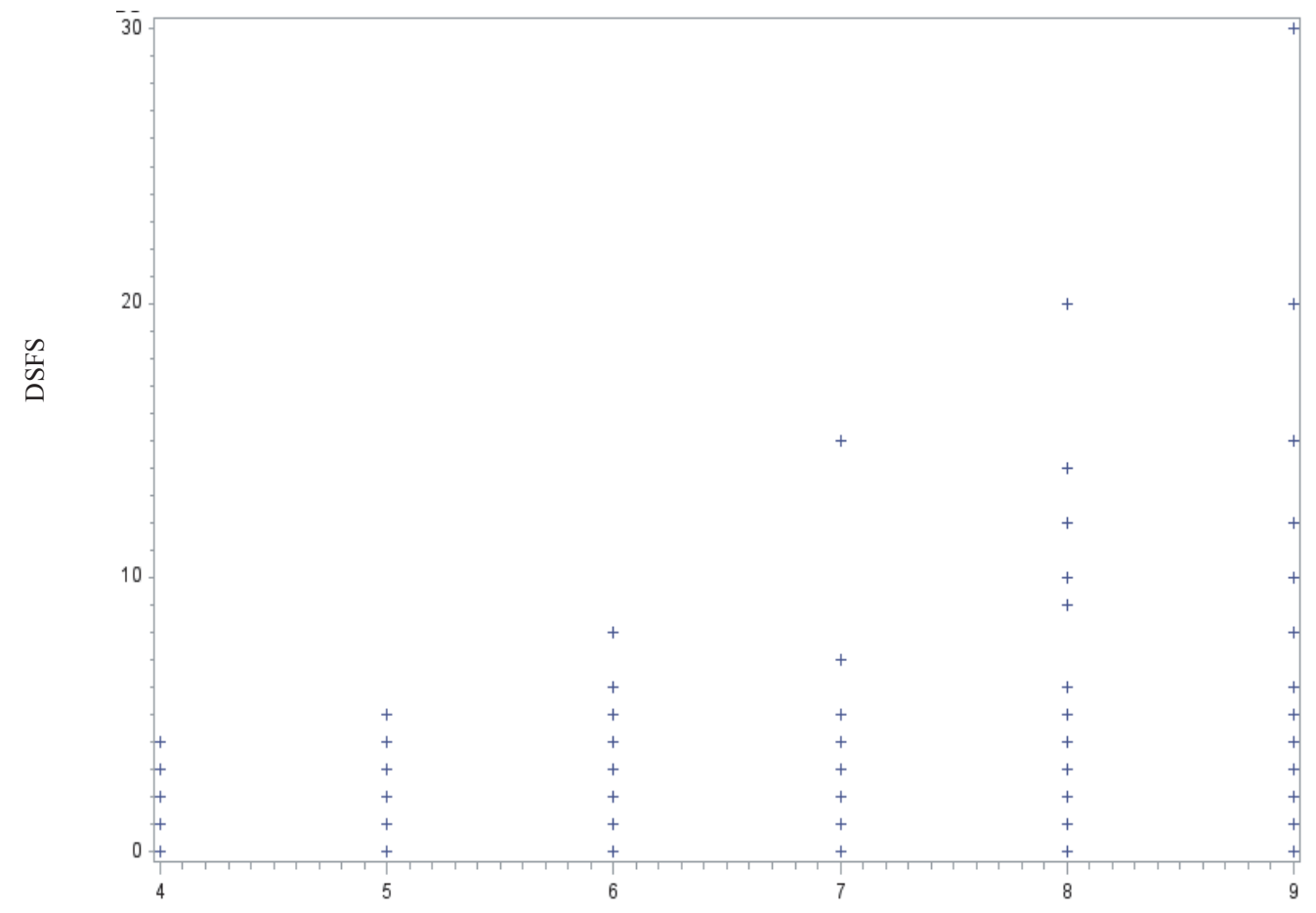

Number of bib changes

Figure 4-Association between Drooling-Severity-and-Frequency Scale (DSFS) scores and the Number of bib changes scores. The Spearman rank correlation coefficient was significantly non-zero, having a positive value of 0.335 . 


\section{4 Correlation between Drooling Quotient (DQ) and Number of bib changes}

To evaluate the association between Drooling Quotient (DQ) scale and Number of bib changes, the measures obtained during the single assessment session were compared. Figure 5 shows a scatter plot of these measures in the 155 patients. To characterize the association between these measures, the non-parametric Spearman rank correlation coefficient was computed. It was found to be significantly $(\mathrm{P}=0.005)$ non-zero, having a positive value of 0.227 , indicating a weak association between DQ and Number of bib changes.

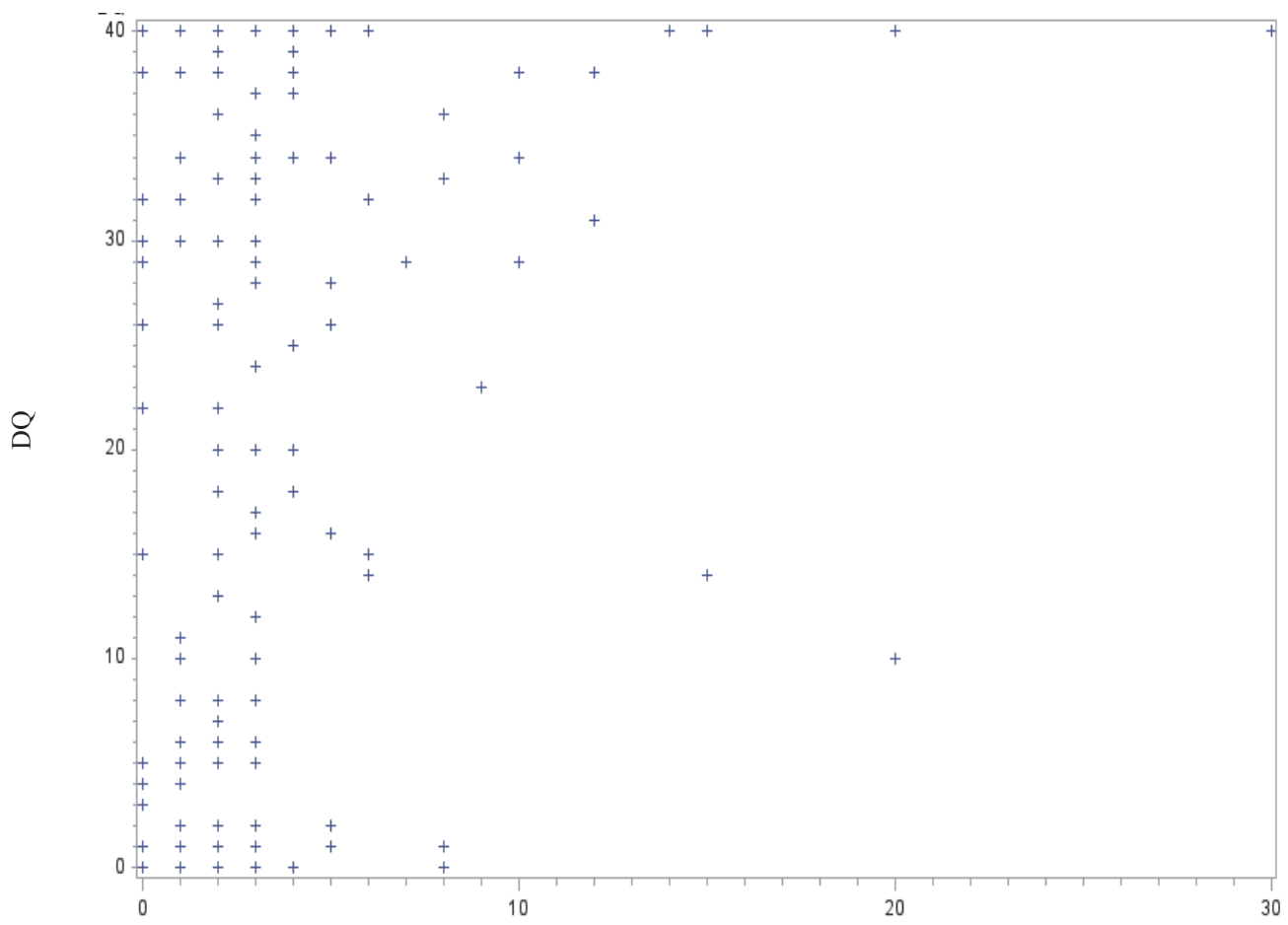

Number of bib changes

Figure 5- Association between Drooling- Quotient (DQ) scores and the Number of bib changes scores. The Spearman rank correlation coefficient was significantly non-zero, having a positive value of 0.227 . 


\subsection{Correlation between Drooling Quotient (DQ) and Drooling Severity}

To evaluate the association between the Drooling Quotient (DQ) score and Drooling Severity score, the measures obtained during the single assessment session were compared. Drooling severity is a subcomponent of the Drooling Severity and Frequency Scale. Figure 6 shows a scatter plot of these measures in the 155 patients. To characterize the association between these measures, the non-parametric Spearman rank correlation coefficient was computed. It was found to be significantly $(\mathrm{P}<0.001)$ non-zero, having a positive value of 0.898 , indicating high level of association between DQ and Drooling Severity.

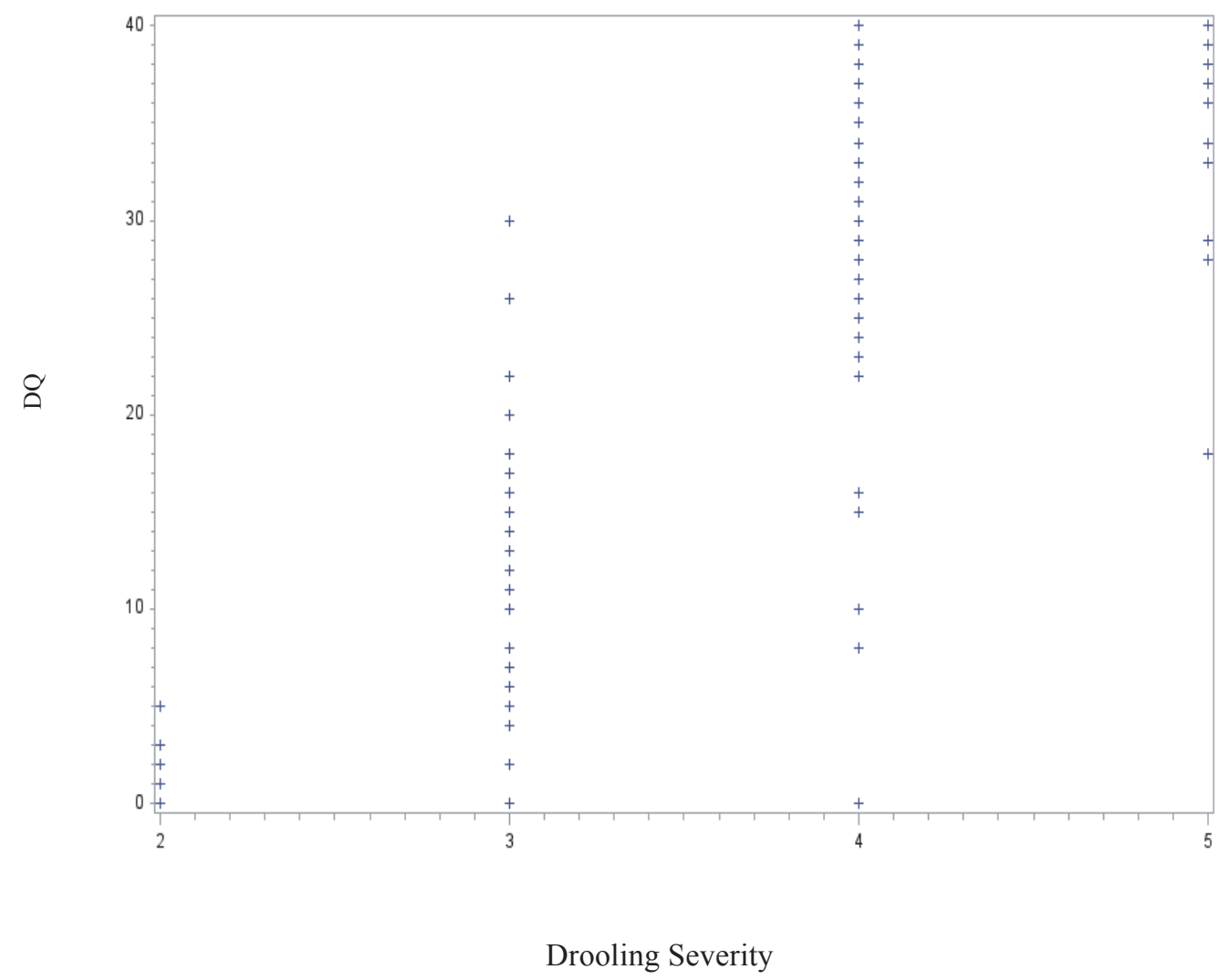

Figure 6- Association between Drooling-Quotient (DQ) scores and Drooling- Severity scores. The Spearman rank correlation coefficient was significantly non-zero, having a positive value of 0.898 . 


\subsection{Correlation between Drooling Quotient (DQ) and Drooling Frequency}

To evaluate the association between the Drooling Quotient (DQ) score and Drooling Frequency score, the measures obtained during the single assessment session were compared. Drooling Frequency is a subcomponent of the Drooling Severity and Frequency Scale. Figure 7 shows a scatter plot of these measures in the 155 patients. To characterize the association between these measures, the non-parametric Spearman rank correlation coefficient was computed. It was found to be significantly $(\mathrm{P}<0.001)$ non-zero, having a positive value of 0.653 , indicating high level of association between DQ and Drooling Frequency.

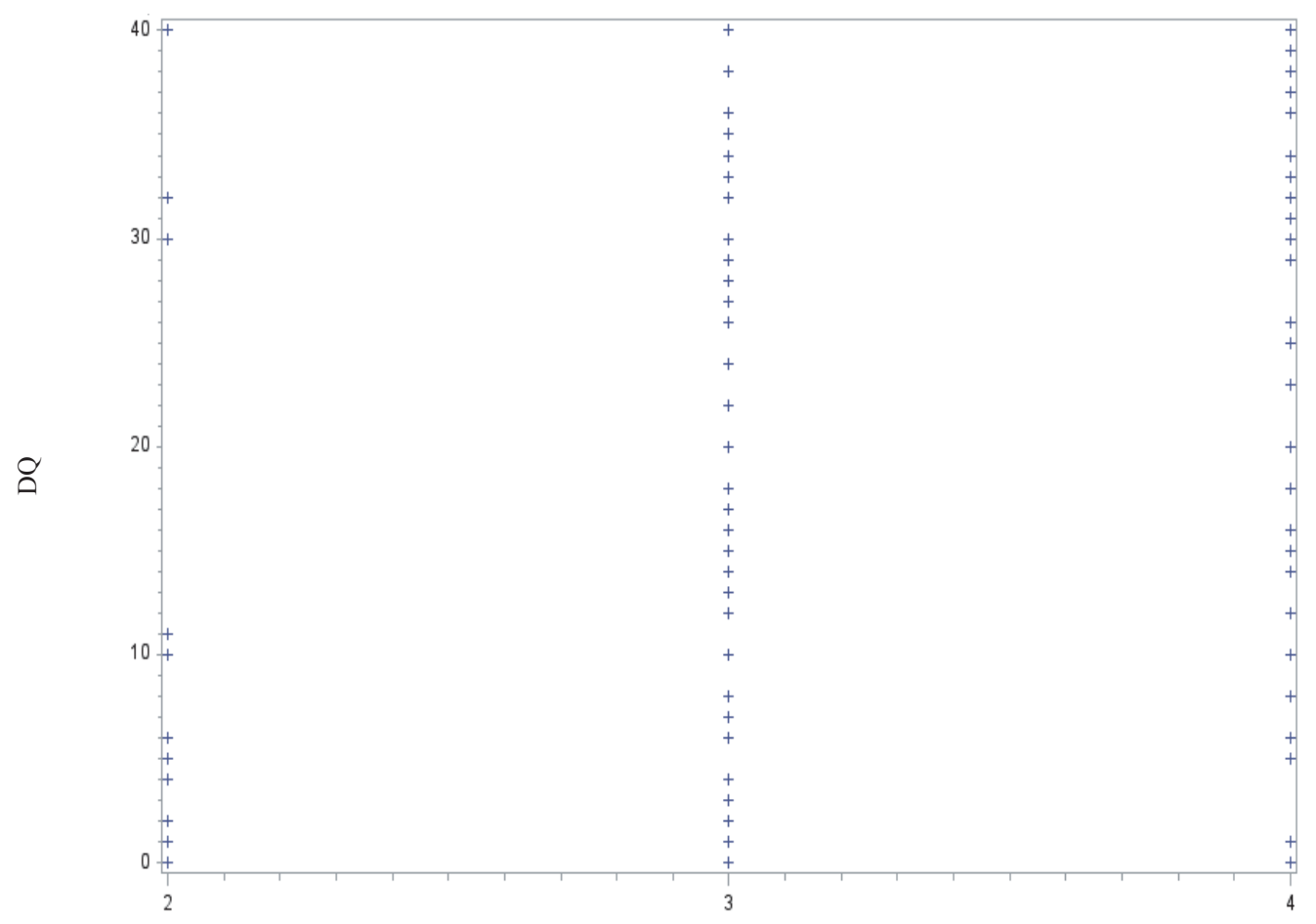

Drooling Frequency

Figure 7- Association between Drooling-Quotient (DQ) scores and Drooling-Frequency scores. The Spearman's rank correlation coefficient was significantly non-zero, having a positive value of 0.653 . 


\subsection{Correlation between Drooling Quotient and other measures}

This section examines whether the associations estimated above might have been influenced by gender, age, any underlying neurological disorder, or any developmental delays. Table 8 shows the Spearman rank correlation coefficient of different measures among these different sub groups. The results show that there were no significant difference between males and females. Also, there were no significant differences between the two age groups (less than or greater than 12 years old). (Table 8 )

Finally, the results show that associations between the drooling measures was very similar among patients with different diagnoses. However, this was only assessed in patients with neurological disorders and developmental delays. Since the number of patients with other diagnoses was small, other correlations were not evaluated statistically. 
Table 8- Correlation between DQ and other measures in different subgroups

\begin{tabular}{|c|c|c|c|c|c|c|}
\hline \multirow{3}{*}{ DQ } & Male & Female & $>12$ & $<12$ & Neurological & Developmental \\
\hline & \multirow[t]{2}{*}{$\mathrm{n}=\mathbf{8 1}$} & \multirow[t]{2}{*}{$n=74$} & Years & Years & Disorder & \multirow[t]{2}{*}{ Delay } \\
\hline & & & $n=48$ & $\mathrm{n}=107$ & $n=62$ & \\
\hline \multirow{3}{*}{ DSFS } & 0.899 & 0.883 & 0.877 & 0.884 & 0.9 & 0.888 \\
\hline & & & & & & \\
\hline & $<.001$ & $<.001$ & $<.001$ & $<.001$ & $<.001$ & $<.001$ \\
\hline Number of & 0.308 & 0.236 & 0.137 & 0.299 & 0.271 & 0.155 \\
\hline changes & 0.0051 & 0.425 & $<.349$ & 0.0017 & 0.032 & 0.22 \\
\hline Drooling & 0.899 & 0.903 & 0.911 & 0.889 & 0.893 & 0.887 \\
\hline severity & $<.001$ & $<.001$ & $<.001$ & $<.001$ & $<.001$ & $<.001$ \\
\hline Drooling & 0.67 & 0.622 & 0.639 & 0.647 & 0.659 & 0.69 \\
\hline Frequency & $<.001$ & $<.001$ & $<.001$ & $<.001$ & $<.001$ & $<.001$ \\
\hline
\end{tabular}




\subsection{Summary}

The results showed that there was a strong association between the subjective DSFS score and the objective DQ scale, as indicated by a high positive Spearman rank correlation coefficient of 0.886 that was significantly different from zero. There was a somewhat weaker moderate association between the 2 subjective measures (the DSFS and number of bib changes). However, there was a weak association between the Drooling Quotient and the Number of bib changes. The Drooling Severity subcomponent of DSFS also showed a higher association with DQ than Drooling Frequency.

The results also showed that there were no significant differences in associations between subjective and objective responses in children with neurological disorders, and between those with developmental delays, suggesting that etiology does not strongly influence correlations between the objective and subjective assessments. 


\section{Chapter 6: Discussion}

\subsection{Summary}

The purpose of this study was to examine whether there is an association between objective measurement of the Drooling Quotient and subjective measurements of drooling (severity and frequency scale and number of bib changes). This thesis tested the hypothesis that there was a significant positive correlation between (i) the Drooling Quotient, (ii) the Drooling Severity and Frequency Scale (DSFS), and (iii) the number of bib changes. If a significant positive association could be established, then more-easily-obtained subjective questionnairebased measures (Drooling Severity and Frequency Scale and number of bib changes in a day) would be able to be used for guidance of clinical decisions instead of the more time-consuming the DQ measure.

The Drooling Quotient is a reliable and validated objective method of drooling measurement. Drooling can be assessed using DQ, which results in a reliable outcome on severity and frequency of drooling (van Hulst et al., 2012). However, it is not feasible in all patients with drooling due to the long period of assessment, which is required in order to obtain an accurate score. In addition, drooling severity varies during daily life situations. Therefore, its impact on quality of life would be better evaluated through subjective methods. Parents' opinions on severity and frequency of drooling, which can be measured using DSFS and number of bib changes, plays a significant role in evaluating treatment outcome.

In current study, the positive correlation coefficient between DQ and DSFS was high indicating by DSFS could be used for guidance of clinical decisions instead of the more time- 
consuming DQ. However, the spearman's rank correlation indicated that there was a higher positive association between DQ and Drooling Severity than between DQ and Drooling Frequency. This suggests that for guidance of clinical decisions, the Drooling Severity subcomponent of the DSFS might be used by itself to assess drooling.

The results also showed that associations between measurements in patients with neurological disorders and of those with developmental delays were similar to all patients. Similarly, associations remained similar regardless of patient age (i.e., less than or greater than 12 years of age).

Although in this study parents often used the number of bib changes to evaluate drooling changes each day rather than other methods, results revealed a rather weak association between DQ and number of bib changes. This suggests that the number of bib changes would not effectively characterize drooling status as well as the DQ for the DSFS. This could be due to recall bias, which results in incorrect estimates regarding the number of times parents/caregivers changed the bibs during a day. In addition, since standard-sized bibs were not used in this study, use of different size of bibs may have increased result variability. Social factors are of importance as well, and could have affected the number of times bibs were changed.

To facilitate measurement procedure for Drooling Quotient, two trained researchers participated. The inter-rater reliability (0.99) was satisfactory, indicating consistent measurements between the two researchers. 


\subsection{Comparison to other studies}

To the best of my knowledge, this is the first study of the association between objective measurement of DQ and the subjective measurements of DSFS, and number of bib changes. The studies reviewed in chapter two demonstrated that a combination of objective and subjective assessments is a useful method to evaluate drooling reduction, but these studies have limitations and new studies should be conducted to fulfil the need for an effective assessment method to quantify drooling better.

DQ is a semi quantitative observational method of assessment that has been used in different studies on interventions for drooling control. This objective method was used along with other subjective assessment tools to have an accurate evaluation of the drooling reduction after interventions. In most of the studies, agreement between DQ and subjective scales was not evaluated.

Jongerius (2005) in a study evaluated the effect of Botulinum toxin using DQ, TDS, and VAS to measure drooling reduction after injections, although their subjective and objective results were similar to each other, correlation between the measures was not evaluated statistically. Also, they used subjective scales of VAS and TDS, which are different from subjective measures in current study. Thus, direct comparison cannot be made.

Nordgarden et al. (2012) used DQ, VAS, and Cotton rolls to measure drooling severity and flow rate in a study on Botulinum toxin for drooling. Their results showed discrepancies between subjective and objective responses. However, no statistical analysis was performed. Since their scales and study procedures were very different from those used in this thesis, comparisons cannot be made. 
Van Hulst (2012) in a study on interventions for drooling control, assessed the correlation between VAS and DQ during activity and at rest. The Pearson's coefficient correlation between VAS and DQ versions showed a weak correlation between the measures suggesting that VAS may not be as useful as DQ to guide clinical management of drooling. My results, however, showed a strong association between DSFS and DQ indicating that DSFS could be used to guide clinical drooling management. Van Hulst also found a stronger correlation between DQ during activity and VAS compared to DQ at rest. In the current study, the relation between subjective measures with different versions of DQ was not assessed. Their subjective measures and evaluation procedures were also different from this study.

Lin et al. (2008) in a study on Botulinum toxin used Drooling Severity and Frequency Scale and Drooling Quotient. Results showed significant between-group differences in DQ and DSFS at follow up sessions. Previously, Hein et al. (1996) also measured the severity of drooling using severity and frequency scale along with DQ in a study on drooling control. They reported similar ratings in subjective and objective evaluations, although, their scales are similar to the current study, but the study procedures were totally different. Also, Correlation between these scales was not statistically evaluated. Moreover, in the current study, measurements were performed only at baseline, while they measured drooling pre and post- interventions and at follow-ups. So, no direct comparison could be made.

\subsection{Study limitations}

There are several limitations for the current study. With respect to the saliva severity that varies day to day and hour to hour, the Drooling Quotient that is obtained during a ten minute interval cannot realistically reflect drooling severity throughout a full day. Furthermore, the 
high level of subjectivity of questionnaire-based methods of assessments can affect their validity and reliability. With regard to the limitations of subjective and objective methods, the results of the study cannot show that the combination of these scales can provide a reliable and preferred scale to measure drooling reduction on applied treatment outcome. Further investigations are needed to assess accuracy of the scales.

In addition to the results of reliability of subjective assessments that are based on parents/caregivers opinions, there exist a bias in parents who report the number of times that bibs need to be changed during a day, unless specific criteria were specified relating to how the decision to change a bib was made. Thus, the results on number of bib changes should be interpreted cautiously.

Since severity of saliva varies depending on whether or not a patient is focusing on swallowing, drooling episodes are different at rest and when a patient is concentrating on another activity. Therefore, Drooling Quotient scores during activity is different from DQ scores at rest. In this study, associations between DQ at rest and during an activity were not assessed separately.

\subsection{Study significance}

The results of this study were important clinically. They supported the research hypothesis that the Drooling Quotient and the Drooling Severity and Frequency Scale were positively correlated and the more easily obtained DSFS score could be used to guide clinical management of drooling. However, the association between the Drooling Quotient and number 
of bib changes was not significant. This suggest that the number of bib changes should not be used for such clinical purposes.

The Drooling Quotient has been shown to be useful in assessing drooling reduction during interventions in patients with developmental disabilities, However, with respect to the saliva production that varies during activity and at rest, ideally DQ should be measured in two observation sessions during activity (when patient is distracted from swallowing) and at rest (when the patient is focused). Indeed, the procedure is time consuming and frustrating for both therapists and disabled patients. Besides, it requires a long period of observation to obtain an accurate drooling score. Moreover, DQ measurement process cannot be performed in patients suffering from severe neuromuscular disabilities.

The results of this study are significant because they show that there is a high level of agreement between this objective DQ scale and the Drooling Severity and Frequency Scale, which means the DSFS can be used to guide clinical management of drooling. This finding will fulfill the need for a convenient and appropriate way to assess drooling in those patients with severe developmental disabilities who are not able to follow DQ procedures. Based on the results, DSFS scale is thought to be a useful subjective method of drooling measurement that can measure changes in drooling based on the parents/caregivers evaluation, while it appears to preserve the same validity and reliability of Drooling Quotient. It saves time and it is more easily used in the clinic to evaluate the effect of interventions.

Previous studies have mentioned that use of subjective drooling ratings from parents was not reliable enough for decision making on interventions in clinical settings and they suggested that an objective method should be used; in this study, the strong positive association found 
between DQ and DSFS provides evidence that Drooling Severity and Frequency Scale estimates are as affective as DQ estimates in a clinical setting. Indeed, my promising results show that a questionnaire based evaluation of Drooling Severity and Frequency is a useful subjective assessment tool that can be used for clinical purposes and in future studies on drooling control.

On the other hand, the low association between DQ and the number of bib changes does not support the hypothesis that this subjective scale and DQ are correlated. Thus the high variability among responses indicated that this scale can only provide a rough estimate of drooling severity, and that it should not be used to guide clinical management of drooling. 


\section{Chapter 7: Conclusion}

\section{1 Conclusion and contributions to knowledge}

This study showed that there was a significant and positive correlation between the objective Drooling Quotient (which is a direct observational method) and the Drooling Severity and Frequency scale (which is a subjective questionnaire-based scale based on parents or caregivers ratings). Results show that the Drooling Severity and Frequency Scale can be used in drooling patients, even in those with neurological disabilities that would make assessment of the Drooling Quotient very difficult. The Drooling Severity and Frequency Scale has been shown to be a quicker and more easily obtained measure of drooling that can be used to help guide clinical management of drooling, both in a time constrained- clinical setting, and in future studies on clinical interventions.

This thesis is the first time that association of objective and two subjective scales has been evaluated in large number of subjects. The sample size was homogenous in that all participants were not receiving interventions. The results also showed that the strong positive association between the DQ and DSFS applied in all patients, even those with different types of neuromuscular disorders or developmental disabilities, and they appeared to be largely independent of age.

\subsection{Future recommendations}

Since there is no evidence for validity and accuracy of available objective and subjective scales, it would be useful to conduct a large scale cohort study on children with drooling to 
assess the validity and reliability of available objective and questionnaire-based assessment methods. It would also be important to assess questionnaire based scales related to assessment of quality of life and the impact of drooling on children's and care givers' life pre- and postinterventions. It would also be interesting to evaluate associations between quality of life measures with DQ or other objective scales, with DQ measures during activity and at rest, and with the Drooling Severity and Frequency scale. In such studies, attempts should be made to educate parents/ caregivers before completing the questionnaires, including specifying how to rate the severity and frequency of drooling, and how to better monitor when decisions about changes of bibs or clothing are made.

Finally, it is useful for future studies on drooling control to develop and validate an unobtrusive quantitative objective scale, which is easy to perform for all patients with neuromuscular and developmental disabilities and which would be useful and practical for the therapist to assess drooling reduction and judge treatment outcomes better. 


\section{References:}

Alrefai, A. H., Aburahma, S. K., \& Khader, Y. S. (2009). Treatment of sialorrhea in children with cerebral palsy: a double-blind placebo controlled trial. Clin Neurol Neurosurg, 111(1), 79-82. doi: 10.1016/j.clineuro.2008.09.001

Basciani, M., Di Rienzo, F., Fontana, A., Copetti, M., Pellegrini, F., \& Intiso, D. (2011). Botulinum toxin type B for sialorrhoea in children with cerebral palsy: a randomized trial comparing three doses. Dev Med Child Neurol, 53(6), 559-564. doi: 10.1111/j.14698749.2011.03952.x

Bothwell, J. E., Clarke, K., Dooley, J. M., Gordon, K. E., Anderson, R., Wood, E. P., . . . Camfield, P. R. (2002). Botulinum toxin A as a treatment for excessive drooling in children. Pediatr Neurol, 27(1), 18-22.

Burton, M. J., Leighton, S. E., \& Lund, W. S. (1991). Long-term results of submandibular duct transposition for drooling. J Laryngol Otol, 105(2), 101-103.

Chang, C. J., \& May-Kuen Wong a, A. (2001). Intraductal laser photocoagulation of the bilateral parotid ducts for reduction of drooling in patients with cerebral palsy. Plast Reconstr Surg, 107(4), 907-913.

Costanzo, L. S. (2006). Physiology. Philadelphia, Penns.: Saunders Elsevier.

Daniel, S. J. (2012). Multidisciplinary management of sialorrhea in children. Laryngoscope, 122 Suppl 4, S67-68. doi: http://dx.doi.org/10.1002/lary.23803

$\begin{array}{llll}\text { Dorland's } \quad \text { illustrated } & \text { medical } & \text { dictionary. } & \text { (2007). }\end{array}$ http://www.credoreference.com/book/ehsdorland 
Ekedahl, C., \& Hallen, O. (1973). Quantitative measurement of drooling. Acta Otolaryngol, 75(5), 464-469.

Ellies, M., Rohrbach-Volland, S., Arglebe, C., Wilken, B., Laskawi, R., \& Hanefeld, F. (2002). Successful management of drooling with botulinum toxin A in neurologically disabled children. Neuropediatrics, 33(6), 327-330. doi: 10.1055/s-2002-37084

Erasmus, C. E., Scheffer, A. R., van Hulst, K., van Limbeek, J., van den Hoogen, F. J., Rotteveel, J. J., \& Jongerius, P. H. (2011). Does motor performance matter in botulinum toxin efficacy for drooling Pediatr Neurol, 45(2), 95-99. doi: 10.1016/j.pediatrneurol.2011.02.011

Erasmus, C. E., Van Hulst, K., Rotteveel, L. J., Jongerius, P. H., Van Den Hoogen, F. J., Roeleveld, N., \& Rotteveel, J. J. (2009). Drooling in cerebral palsy: hypersalivation or dysfunctional oral motor control Dev Med Child Neurol, 51(6), 454-459. doi: $10.1111 / j .1469-8749.2008 .03243 . x$

Fairhurst, C. B., \& Cockerill, H. (2011). Management of drooling in children. Arch Dis Child Educ Pract Ed, 96(1), 25-30. doi: 10.1136/adc.2007.129478

Gok, G., Cox, N., Bajwa, J., Christodoulou, D., Moody, A., \& Howlett, D. C. (2013). Ultrasound-guided injection of botulinum toxin A into the submandibular gland in children and young adults with sialorrhoea. British Journal of Oral and Maxillofacial Surgery, 51(3), 231-233. doi: http://dx.doi.org/10.1016/j.bjoms.2012.07.012

Hassin-Baer, S., Scheuer, E., Buchman, A. S., Jacobson, I., \& Ben-Zeev, B. (2005). Botulinum toxin injections for children with excessive drooling. J Child Neurol, 20(2), 120-123. 
Hay, N., \& Penn, C. (2011). Botox $((\mathrm{R}))$ to reduce drooling in a paediatric population with neurological impairments: a Phase I study. Int J Lang Commun Disord, 46(5), 550-563. doi: 10.1111/j.1460-6984.2011.00010.x

Heine, R. G., Catto-Smith, A. G., \& Reddihough, D. S. (1996). Effect of antireflux medication on salivary drooling in children with cerebral palsy. Dev Med Child Neurol, 38(11), 1030-1036.

Hockstein, N. G., Samadi, D. S., Gendron, K., \& Handler, S. D. (2004). Sialorrhea: a management challenge. Am Fam Physician, 69(11), 2628-2634.

Hupp, J. R., Tucker, M. R., \& Ellis, E. (2008). Contemporary oral and maxillofacial surgery. St. Louis, Mo. :: Mosby Elsevier.

Jeung, I. S., Lee, S., Kim, H. S., \& Yeo, C. K. (2012). Effect of botulinum toxin a injection into the salivary glands for sialorrhea in children with neurologic disorders. Ann Rehabil Med, 36(3), 340-346. doi: 10.5535/arm.2012.36.3.340

Johnson, H. M., Reid, S. M., Hazard, C. J., Lucas, J. O., Desai, M., \& Reddihough, D. S. (2004). Effectiveness of the Innsbruck Sensorimotor Activator and Regulator in improving saliva control in children with cerebral palsy. Dev Med Child Neurol, 46(1), 39-45.

Jongerius, P. H., Rotteveel, J. J., van den Hoogen, F., Joosten, F., van Hulst, K., \& Gabreels, F. J. (2001). Botulinum toxin A: a new option for treatment of drooling in children with cerebral palsy. Presentation of a case series. Eur J Pediatr, 160(8), 509-512.

Jongerius, P. H., van Hulst, K., van den Hoogen, F. J., \& Rotteveel, J. J. (2005). The treatment of posterior drooling by botulinum toxin in a child with cerebral palsy. $J$ Pediatr Gastroenterol Nutr, 41(3), 351-353. 
Lehman, A. (2005). JMP For Basic Univariate And Multivariate Statistics: A Step-by-step Guide: SAS Institute.

Limbrock, G. J., Fischer-Brandies, H., \& Avalle, C. (1991). Castillo-Morales' orofacial therapy: treatment of 67 children with Down syndrome. Dev Med Child Neurol, 33(4), 296-303.

Lin, Y. C., Shieh, J. Y., Cheng, M. L., \& Yang, P. Y. (2008). Botulinum toxin type A for control of drooling in Asian patients with cerebral palsy. Neurology, 70(4), 316-318. doi: 10.1212/01.wnl.0000300421.38081.7d

Mancini, F., Zangaglia, R., Cristina, S., Sommaruga, M. G., Martignoni, E., Nappi, G., \& Pacchetti, C. (2003). Double-blind, placebo-controlled study to evaluate the efficacy and safety of botulinum toxin type A in the treatment of drooling in parkinsonism. Mov Disord, 18(6), 685-688. doi: 10.1002/mds.10420

Marina, M. B., Sani, A., Hamzaini, A. H., \& Hamidon, B. B. (2008). Ultrasound-guided botulinum toxin A injection: an alternative treatment for dribbling. $J$ Laryngol Otol, 122(6), 609-614. doi: 10.1017/s0022215107008730

Martin, T. J., \& Conley, S. F. (2007). Long-term efficacy of intra-oral surgery for sialorrhea. Otolaryngol Head Neck Surg, 137(1), 54-58. doi: 10.1016/j.otohns.2007.01.034

Mato, A., Limeres, J., Tomas, I., Munoz, M., Abuin, C., Feijoo, J. F., \& Diz, P. (2010). Management of drooling in disabled patients with scopolamine patches. $\mathrm{Br} J$ Clin Pharmacol, 69(6), 684-688. doi: 10.1111/j.1365-2125.2010.03659.x

Mier, R. J., Bachrach, S. J., Lakin, R. C., Barker, T., Childs, J., \& Moran, M. (2000). Treatment of sialorrhea with glycopyrrolate: A double-blind, dose-ranging study. Arch Pediatr Adolesc Med, 154(12), 1214-1218. 
Nordgarden, H., Osterhus, I., Moystad, A., Asten, P., Johnsen, U. L., Storhaug, K., \& Loven, J. O. (2012). Drooling: are botulinum toxin injections into the major salivary glands a good treatment option? J Child Neurol, 27(4), 458-464. doi: 10.1177/0883073811419365

OLIVER, R. G. (1987). OLIVER, R. G. (1987), Theoretical aspects and clinical experience with the palatal training appliance for saliva control in persons with cerebral palsy. Special Care in Dentistry, 7: 271-274. doi: 10.1111/j.1754-4505.1987. Special Care in Dentistry, 7, 271-274.

Peyton Shirley, W., Scott Hill, J., Woolley, A. L., \& Wiatrak, B. J. (2003). Success and complications of four-duct ligation for sialorrhea. International Journal of Pediatric Otorhinolaryngology, 67(1), 1-6. doi: http://dx.doi.org/10.1016/S0165-5876(02)00281-1

Rapp, D. (1988). Management of drooling. Dev Med Child Neurol, 30(1), 128-129.

Reddihough, D., Johnson, H., Staples, M., Hudson, I., \& Exarchos, H. (1990). Use of benzhexol hydrochloride to control drooling of children with cerebral palsy. Dev Med Child Neurol, 32(11), 985-989.

Reid, S. M., Johnson, H. M., \& Reddihough, D. S. (2010). The Drooling Impact Scale: a measure of the impact of drooling in children with developmental disabilities. Dev Med Child Neurol, 52(2), e23-28. doi: 10.1111/j.1469-8749.2009.03519.x

Savarese, R., Diamond, M., Elovic, E., \& Millis, S. R. (2004). Intraparotid injection of botulinum toxin A as a treatment to control sialorrhea in children with cerebral palsy. $\mathrm{Am}$ J Phys Med Rehabil, 83(4), 304-311; quiz 312-304, 336.

Scheffer, A. R., Erasmus, C., K, V. A. N. H., J, V. A. N. L., Rotteveel, J. J., Jongerius, P. H., \& van den Hoogen, F. J. (2010). Botulinum toxin versus submandibular duct relocation for 
severe drooling. Dev Med Child Neurol, 52(11), 1038-1042. doi: 10.1111/j.14698749.2010.03713.x

Schroeder, A. S., Kling, T., Huss, K., Borggraefe, I., Koerte, I. K., Blaschek, A., . . Berweck, S. (2012). Botulinum toxin type A and B for the reduction of hypersalivation in children with neurological disorders: a focus on effectiveness and therapy adherence. Neuropediatrics, 43(1), 27-36. doi: 10.1055/s-0032-1307457

Shirley, W. P., Hill, J. S., Woolley, A. L., \& Wiatrak, B. J. (2003). Success and complications of four-duct ligation for sialorrhea. Int J Pediatr Otorhinolaryngol, 67(1), 1-6.

Sochaniwskyj, A. E. (1982). Drool quantification: noninvasive technique. Arch Phys Med Rehabil, 63(12), 605-607.

Stern, L. M. (1997). Preliminary study of glycopyrrolate in the management of drooling. $J$ Paediatr Child Health, 33(1), 52-54.

Suskind, D. L., \& Tilton, A. (2002). Clinical study of botulinum-A toxin in the treatment of sialorrhea in children with cerebral palsy. Laryngoscope, 112(1), 73-81. doi: 10.1097/00005537-200201000-00014

Tahmassebi, J. F., \& Curzon, M. E. (2003). The cause of drooling in children with cerebral palsy -- hypersalivation or swallowing defect? Int J Paediatr Dent, 13(2), 106-111.

Thomas-Stonell, N., \& Greenberg, J. (1988). Three treatment approaches and clinical factors in the reduction of drooling. Dysphagia, 3(2), 73-78.

van der Burg, J., Jongerius, P., van Limbeek, J., van Hulst, K., \& Rotteveel, J. (2006). Drooling in children with cerebral palsy: a qualitative method to evaluate parental perceptions of 
its impact on daily life, social interaction, and self-esteem. Int J Rehabil Res, 29(2), 179182. doi: 10.1097/01.mrr.0000194395.64396.f1

van Hulst, K., Lindeboom, R., \& Jongerius, P. (2012). Accurate assessment of drooling severity with the 5-minute drooling quotient in children with developmental disabilities. Developmental Medicine \& Child Neurology, 54(12), 1121-1126. doi: 10.1111/j.14698749.2012.04428.x

Wu, K. P., Ke, J. Y., Chen, C. Y., Chen, C. L., Chou, M. Y., \& Pei, Y. C. (2011). Botulinum toxin type A on oral health in treating sialorrhea in children with cerebral palsy: a randomized, double-blind, placebo-controlled study. J Child Neurol, 26(7), 838-843. doi: $10.1177 / 0883073810395391$

Yam, W. K., Yang, H. L., Abdullah, V., \& Chan, C. Y. (2006). Management of drooling for children with neurological problems in Hong Kong. Brain Dev, 28(1), 24-29. doi: 10.1016/j.braindev.2005.03.008 


\section{Appendix}

Drooling Severity and Frequency Scale

Drooling severity

1- Dry (never drool)

2- Mild (only lips wet)

3- Moderate (wet on lips and chin)

4- Sever (drools to extent that clothing becomes damp)

5- Profuse (hands, tray and objects wet)

Drooling frequency

1- Never drools

2- Occasionally (not every day)

3- Frequently (part of everyday)

4- Constantly 